\title{
WIENER INDEX OF ROUGH CO-ZERO DIVISOR GRAPH OF A ROUGH SEMIRING
}

\author{
B. Praba ${ }^{1}$ and M. Logeshwari ${ }^{2 *}$ \\ ${ }^{1}$ Sri Sivasubramaniya Nadar College of Engineering, Chennai, Tamil Nadu, India. E-mail: prabab@ssn.edu.in \\ ${ }^{*}$ Sri Sivasubramaniya Nadar College of Engineering, Chennai, Tamil Nadu, India. E-mail: \\ logeshjimail@gmail.com.
}

\begin{abstract}
In this proposed article we consider an approximation space $I=(U, R)$, where $U$ denotes nonempty finite set of objects and $\mathrm{R}$ be an arbitrary equivalence relation defined on $\mathrm{U}$. The Rough Co-zero divisor graph $\mathrm{G}\left(\mathrm{Z}^{*}(J)\right)$ of a Rough Semiring $(\mathrm{T}, \Delta, \nabla)$ on I corresponding to the Rough ideal is taken for study. The degree of each of the vertices and distance of any two vertices in $G\left(Z^{*}(J)\right)$ are computed. Based on the degree of vertices a Partition graph $P\left(Z^{*}(J)\right)$ is defined. This Partition graph is used to find the Wiener index of $G\left(Z^{*}(J)\right)$. The main advantage of partition graph is that all the graph theoretical parameters can be computed for any Rough Co-zero divisor graph with $2^{\mathrm{n}-\mathrm{m}} \cdot 3^{\mathrm{m}}-2,1 \leq \mathrm{m} \leq \mathrm{n}$. An analysis of disease symptom relationship is made through the defined parameters. All of the concepts are embellished with suitable examples. AMS Classification: 05C12, $05 \mathrm{C} 05$
\end{abstract}

Keywords: Degree, Distance, Rough Co-Zero Divisor Graph, Partition Graph, Wiener Index.

\section{INTRODUCTION}

Wiener index is the primary graph theoretical index to be used in Chemistry. It was introduced by Harold Wiener in 1947. Mathematical studies of Wiener index started in the year 1970 [1];[2]. The concept of Wiener index is a boundary between Algebraic graph theory and Chemistry.

The introduction of Rough set theory was proposed by Pawlak [12] in 1982 which is tool for Medalling with imperfect knowledge, in particular with vague concepts in the information systems and it is defined as a pair called lower and upper approximation.

Rough set theory is one such tool and has more advantage than Fuzzy set theory and any other theory like probability theory, evidence theory, etc and It provides efficient methods, algorithms and tools for finding hidden patterns in data. For a subset of the universe, Rough set is an ordered pair of lower and upper approximations. The research on Rough set theory and its application in various fields have attracted the attention of researchers more and more. Rough set theory is applied in knowledge discovery, feature selection, pattern recognition, machine learning, medicine, and telecommunications.

In 201[5];[8-10] considered an approximation space $I=(U, R)$ where $U$ is nonempty finite set of objects and $R$ is an arbitrary equivalence relation on $U$. With respect to the two operations $\Delta$ and $\nabla$ the set of all Rough sets $T$ on $U$ is proved to be a Semiring called namely Rough Semiring. The ideals of this Rough Semiring are also studied widely [5].

Received JUN 28, 2021

www.dynamicpublishers.com;

www.dynamicpublishers.org;
ISSN1056-2176(Print); ISSN 2693-5295 (online) $\$ 15.00$ (C)Dynamic Publishers, Inc. https://doi.org/10.46719/dsa202130.09.08 
Hua [6];[7] designed the concept of Co-zero divisor graph, denoted by $\Gamma^{\prime}(R)$, on a commutative ring $R$. Let by $\mathrm{W}^{*}(R)$ denote non-unit elements of $R$. In the vertex set $\Gamma^{\prime}(R)$ is $\mathrm{W}^{*}(R)$ and for two distinct vertices $a$ and $b$ in $\mathrm{W}^{*}(R), a$ is adjacent to $b$ if and only if $a \epsilon(b)$ and $b \epsilon(a)$, where $(c)$ is an ideal generated by the element $c$.

In 1988 Mohar and Pisanki they derived algorithms to calculate the Wiener index of graphs and trees. In 2013 Vijayabarathi and Anjaneyulu also have made a study on the Wiener index of graphs and its chemical applications. M. Fischerman, et.al (characterized the trees which minimizes and maximizes the Wiener index under different conditions and Stevanovic discussed on the maximization of Wiener index of graphs with maximum degree. A study on edge - Wiener index of a graph is made by authors P. Danklemann et.al.[3]; [4] Motivation of this study is to discuss the Algebraic graph theoretic concepts on the Rough semiring $(T, \Delta, \nabla)$. The complexity of this study will increase for large values of $n$ and $m$. In this work, the complexity is made simpler by defining a partition graph $P\left(Z^{*}(J)\right)$ corresponding to $G\left(Z^{*}(J)\right)$, in which the vertices are divided into seven partitions. This partition graph is obtained by defining suitable partition in the vertices of $G\left(Z^{*}(J)\right)$. Hence vertices of same degree will fall into same partition. The objective of these graph theoretical parameters is computed using partition graph corresponding to a Rough Co-zero divisor graph.

In section 2 we provide with a basic definitions and notations and in section 3 we define the partition graph of $G\left(Z^{*}(J)\right)$ and in section 3.1 we find the degree's of the vertices in $G\left(Z^{*}(J)\right)$. In section 3.2. we define partition graph of Rough Co-zero divisor graph. Finally section 3.3 explains the Wiener index of $G\left(Z^{*}(J)\right)$ using the partition graph. An analysis of disease symptom relationship is made through the defined parameters in section 4 followed by a conclusion.

\section{2 . BASIC DEFINITION AND NOTATION}

\subsection{Graph Theory}

Graph theory plays a vital role in modelling real time problems with which a suitable solution can be obtained. The Graph theoretical parameters are widely used in data flow diagram, decision making ability, and displays relationships among objects, easy alterations and modifications in the existing system etc.

Let graph $S$, connected undirected graph with $V(S)=\left\{v_{1}, v_{2}, \ldots v_{n}\right\}$ and $E(S)=\left\{e_{1}, e_{2}, \ldots e_{n}\right\}$ the distance between any two vertices $v_{i}$ and $v_{j}$ denoted by $d\left(v_{i}, v_{j}\right)$ is the length of a shortest path between $v_{i}$ and $v_{j}$ in $S$. The wiener index of a graph $S$ denoted by $W(S)$ is the sum of the distances between all pair of vertices of $S$.

(i.e.) $W(S)=\sum_{i<j} d\left(v_{i}, v_{j}\right)$

The degree of a vertex of a graph is the number of edges that are incident to the vertex. The degree of a vertex is denoted by $\operatorname{deg}(v)$. 


\subsection{Rough Set Theory}

Let $U$ be a nonempty set which is finite and $R$ be an arbitrary equivalence relation defined on $U$ then $I=(U, R)$ is called an approximation space for $x,[x]_{R}=\{y \in U \mid(x, y) \in R\}$ is said to be an equivalence class. Then for $X \subseteq U$, let $R S(X)=(\underline{R}(X), \bar{R}(X))$ be the rough set, where $\underline{R}(X)=$ $\left\{x \in U \mid[x]_{R} \subseteq X\right\}$ is said to be a lower approximation and higher approximation defined as $\bar{R}(X)=\left\{x \in U \mid[x]_{R} \cap X \neq \emptyset\right\}$. Also $T=\{R S(X) \mid X \subseteq U\}$ be the collection of all rough sets.

For any approximation space $\mathrm{I}=(\mathrm{U}, \mathrm{R})$, the set of all Rough sets $\mathrm{T}$ was proved to be a lattice called Rough lattice having praba $\Delta$ and $\operatorname{praba} \nabla$ as its least upper bound and greatest lower bound. Hence $(T, \Delta, \nabla)$ is a semiring called rough semiring [9].

\section{Theorem 2.1.}

Let $\mathrm{I}=(\mathrm{U}, \mathrm{A})$ be an information system where $\mathrm{U}$ be the universal (finite) set and $\mathrm{A}$ be the set of attributes and $\mathrm{T}$ be the set of all rough sets then $(T, \Delta, \nabla)$ is a Semiring.

\section{Definition 2.1}

Let $X, Y \subseteq U$ the praba $\Delta$ is defined as $X=X \cup Y$ if $I W(X \cup Y)=I W(X)+$ $I W(Y)-I W(X \cap Y)$.

\section{Definition 2.2:}

Let $X, Y \subseteq U$ then an element $x \in U$ is called a Pivot element, if $[x]_{p} \nsubseteq X \cap Y$, but $[x]_{p} \cap$ $X \neq \emptyset$ and $[x]_{p} \cap Y \neq \varnothing$. $P_{X \cap Y}$ be the collection of pivot elements.

\section{Definition 2.3:}

praba $\nabla X$ and $Y$ define by $X \nabla Y=\left\{x \mid[x]_{p} \subseteq X \cap Y\right\} \cup P_{X \cap Y}$, where $X, Y \subseteq U$. Identify that every pivot element in $P_{X \cap Y}$ be the representative of specific class.

\section{Definition 2.4:}

The Rough co-zero divisor graph $G\left(Z^{*}(J)\right)=\left(V\left(Z^{*}(J)\right), E\left(Z^{*}(J)\right)\right)$ where $V\left(Z^{*}(J)\right)$ is the set of vertices consisting of the elements of $T^{*}=T-\{R S(\emptyset), R S(U)\}$ and two elements $R S(X)$, $R S(Y) \in V\left(Z^{*}(J)\right)$ are adjacent if and only if $R S(X) \notin R S(Y) \nabla J$ and $R S(Y) \notin R S(X) \nabla J$.

\section{Illustration 2.1:}

Let $U=\left\{x_{1}, x_{2}, x_{3}, x_{4}, x_{5}, x_{6}\right\}$ and let $\left\{X_{1}, X_{2}, X_{3}\right\}$ are the equivalence classes induced by an equivalence relation $R$ on $U$ such $X_{1}=\left\{x_{1}, x_{3}\right\}, X_{1}=\left\{x_{2}, x_{4}, x_{6}\right\}$ and $X_{1}=\left\{x_{5}\right\}$ 


$$
V\left(Z^{*}(J)\right)=\left\{R S\left(x_{1}\right), R S\left(x_{2}\right), R S\left(X_{1}\right), R S\left(X_{2}\right), R S\left(X_{3}\right), R S\left(x_{1} \cup x_{2}\right), R S\left(X_{1} \cup X_{2}\right), R S\left(X_{1} \cup\right.\right.
$$
$\left.X_{3}\right), R S\left(X_{2} \cup X_{3}\right), R S\left(x_{1} \cup X_{2}\right), R S\left(X_{1} \cup x_{2}\right), R S\left(x_{1} \cup X_{3}\right), R S\left(x_{2} \cup X_{3}\right), R S\left(x_{1} \cup X_{2} \cup\right.$ $\left.\left.X_{3}\right), R S\left(X_{1} \cup x_{2} \cup X_{3}\right), R S\left(x_{1} \cup x_{2} \cup X_{3}\right)\right\} ; B=\left\{x_{1}, x_{2}\right\}, J=\left\{R S\left(x_{1}\right), R S\left(x_{2}\right), R S\left(x_{1} \cup x_{2}\right)\right\}$

Figure 1 represents the Rough co-zero divisor graph for $n=3$ and $m=2$.

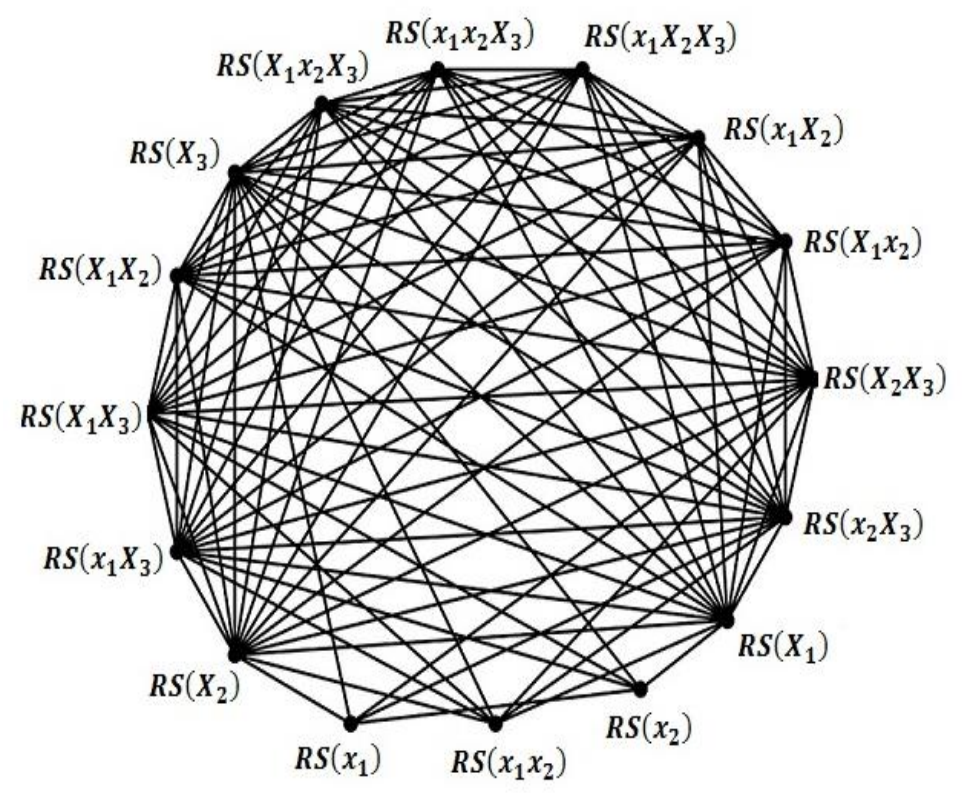

Figure 1: Rough Co-Zero Divisor Graph for $\mathrm{n}=3$ and $\mathrm{m}=2$.

\section{Illustration 2.2:}

Let $U=\left\{x_{1}, x_{2}, x_{3}, x_{4}, x_{5}, x_{6}\right\}$ and let $\left\{X_{1}, X_{2}, X_{3}\right\}$ are the equivalence classes induced by an equivalence relation $R$ on $U$ such $X_{1}=\left\{x_{1}, x_{3}\right\}, X_{1}=\left\{x_{2}, x_{4}\right\}$ and $X_{1}=\left\{x_{5}, x_{6}\right\}$

$$
V\left(Z^{*}(J)\right)=\left\{R S\left(x_{1}\right), R S\left(x_{2}\right), R S\left(x_{3}\right), R S\left(X_{1}\right), R S\left(X_{2}\right), R S\left(X_{3}\right), R S\left(x_{1} \cup x_{2}\right), R S\left(x_{1} \cup\right.\right.
$$

$\left.x_{3}\right), R S\left(x_{2} \cup x_{3}\right), R S\left(x_{1} \cup x_{2} \cup x_{3}\right), R S\left(X_{1} \cup X_{2}\right), R S\left(X_{1} \cup X_{3}\right), R S\left(X_{2} \cup X_{3}\right), R S\left(x_{1} \cup\right.$ $\left.X_{2}\right), R S\left(X_{1} \cup x_{2}\right), R S\left(x_{1} \cup X_{3}\right), R S\left(X_{1} \cup x_{3}\right), R S\left(x_{2} \cup X_{3}\right), R S\left(X_{2} \cup x_{3}\right), R S\left(x_{1} \cup X_{2} \cup\right.$ $\left.X_{3}\right), R S\left(X_{1} \cup x_{2} \cup X_{3}\right), R S\left(X_{1} \cup X_{2} \cup x_{3}\right), R S\left(x_{1} \cup x_{2} \cup X_{3}\right), R S\left(x_{1} \cup X_{2} \cup x_{3}\right), R S\left(X_{1} \cup x_{2} \cup\right.$ $\left.\left.x_{3}\right)\right\}$

$$
\begin{gathered}
B=\left\{x_{1}, x_{2}, x_{3}\right\} \\
\left.\left.x_{3}\right) R S\left(x_{1} \cup x_{2} \cup x_{3}\right)\right\}
\end{gathered} \quad, \quad J=\left\{R S\left(x_{1}\right), R S\left(x_{2}\right), R S\left(x_{3}\right), R S\left(x_{1} \cup x_{2}\right), R S\left(x_{1} \cup x_{3}\right), R S\left(x_{2} \cup\right.\right.
$$

Figure 2 represents the Rough co-zero divisor graph for $=m=3$. 


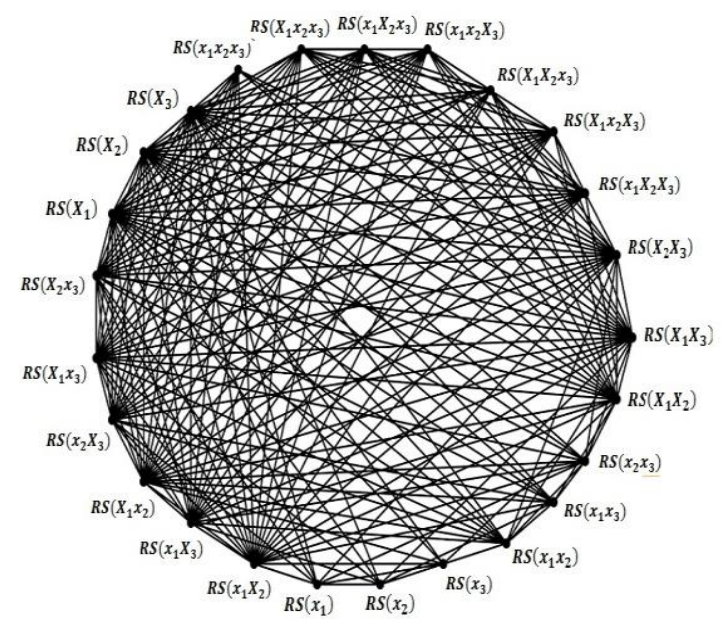

Figure 2: Rough Co-Zero Divisor Graph for $n=m=3$

\section{WIENER INDEX OF A ROUGH CO-ZERO DIVISOR GRAPH}

Throughout this section we assume that $I=(U, R)$. Let $\left\{X_{1}, X_{2}, \ldots X_{n}\right\}$ are the equivalence classes persuaded by $R$ on $U$.We also infer that $m$ equivalence classes $\left\{X_{1}, X_{2}, \ldots X_{m}\right\}$ with cardinality larger than 1 and the remaining $n-m$ equivalence classes $\left\{X_{m+1}, X_{m+2}, \ldots X_{n}\right\}$ have cardinality equal to 1 , where $1<m \leq n$. Let $B=\left\{x_{1}, x_{2}, \ldots x_{m}\right\}$ representative member of the equivalence class having cardinality larger than 1 .

Let $T=\{R S(X) \mid X \subseteq U\}$ be the rough lattice [9] associated with the information system $I$ and $T^{*}=T-\{R S(\varnothing), R S(U)\}$. Moreover let $J=\{R S(X) \mid X \in P(B)\}$ be the rough ideal [5] on $T^{*}$.

\subsection{Degree of Rough Co-Zero Divisor Graph}

In this section we obtain the degree's each vertex of $G\left(Z^{*}(J)\right)$.

\section{Definition 3.1.1:}

Degree of a vertex in $G\left(Z^{*}(J)\right)$ is denoted by $\operatorname{deg}(R S(X))$, is the no. of lines incident with $R S(X)$.The maximum degree of $G\left(Z^{*}(J)\right)$ denoted by $\Delta\left(G\left(Z^{*}(J)\right)\right)$, is defined to be $\Delta\left(G\left(Z^{*}(J)\right)\right)=\max \left\{\operatorname{deg}(R S(X)) \mid R S(X) \in V\left(Z^{*}(J)\right)\right\}$.

Similarly the minimum degree of $G\left(Z^{*}(J)\right)$ denoted by $\Delta\left(G\left(Z^{*}(J)\right)\right)$, is defined to be $\delta\left(G\left(Z^{*}(J)\right)\right)=\min \left\{\operatorname{deg}(R S(X)) \mid R S(X) \in V\left(Z^{*}(J)\right)\right\}$.

\section{Theorem 3.1.1}

The degree of $R S\left(x_{i}\right)$ is $(m-1)\left(2^{n+1-m}\right)+2^{m-1}-m+2^{n-m}-1+\left[(m-1) C_{r}\left(2^{n-m}-\right.\right.$ $\left.1)+(m-1) C_{r}\left(2^{n-m}\right)+\sum_{r=2}^{m-1}\left((m-1) C_{1}+(m-1) C_{2}+\cdots+(m-1) C_{r-1}\right)\right]\left(2^{n-m}\right)$

\section{Proof:}


Let us consider the Rough set corresponding to the pivot elements. Let $P_{1}=\left\{R S\left(x_{i}\right) \mid i=\right.$ $1,2 . . m\}$ the following observations are made.

1. For each $i, R S\left(x_{i}\right)$ is connected to all $R S\left(x_{j}\right)$ for $i \neq j, i, j=1,2 \ldots m$. Number of such elements to which $R S\left(x_{i}\right)$ connected to is $(m-1)$.

2. For each $i, R S\left(x_{i}\right)$ is connected to $R S\left(x_{j} \cup M^{\prime}\right) \cup R S\left(X_{j} \cup M\right)$ for $i \neq j, i, j=1,2 \ldots m$. Number of such elements to which $R S\left(x_{i}\right)$ connected to is $(m-1)\left(2^{n-m+1}-1\right)$.

3. For each $i, R S\left(x_{i}\right)$ is connected to all the elements of the set $\left\{R S\left(Q_{j}\right) \mid Q_{j} \in P(Q)-\right.$ $\left.\emptyset, Q=X_{m+1}, X_{m+2, \ldots} X_{n}\right\}$ for $i \neq j, i, j=1,2 \ldots m$. Number of such elements to which $R S\left(x_{i}\right)$ connected to is $2^{n-m}-1$.

4. We consider the set $\left\{R S\left(x_{1}, x_{2} \ldots x_{r}\right) \mid 1<r<m\right\}, R S\left(x_{i}\right)$ will be connected to all the elements of the form $R S\left(x_{1}, x_{2} \ldots x_{r}\right)$ that does not contain $R S\left(x_{i}\right)$. Number of such elements is given by $2^{m-1}-m$.

5. We consider the set $R S\left(x_{1}, x_{2} \ldots x_{r} \cup M^{\prime}\right) \cup R S\left(X_{1}, X_{2} \ldots X_{r} \cup M\right) \cup R S\left(Q_{r} \cup M\right)$. Number of such elements to which $R S\left(x_{i}\right)$ connected to is $(m-1) C_{r}\left(2^{n-m}-1\right)+$ $(m-1) C_{r}\left(2^{n-m}\right)+\sum_{r=2}^{m-1}\left((m-1) C_{1}+(m-1) C_{2}+\cdots+(m-1) C_{r-1}\right)\left(2^{n-m}\right)$

Therefore for the total number of elements in $V\left(Z^{*}(J)\right)$ to which $R S\left(x_{i}\right)$ is connected to is obtained by adding all the observations. Hence degree of $R S\left(x_{i}\right)$ is

$$
\begin{aligned}
& (m-1)\left(2^{n-m+1}\right)+2^{n-m}-1+2^{m-1}-m+\left[(m-1) C_{r}\left(2^{n-m}-1\right)+(m-\right. \\
& \text { 1) } \left.C_{r}\left(2^{n-m}\right)+\left(2^{n-m}\right) \sum_{r=2}^{m-1}\left((m-1) C_{1}+(m-1) C_{2}+\cdots+(m-1) C_{r-1}\right)\right]
\end{aligned}
$$

\section{Theorem 3.1.2:}

The degree of $R S\left(x_{i} \cup M^{\prime}\right) \cup R S\left(X_{i} \cup M\right)$ is $m\left(2^{n+1-m}-1\right)+2^{m}-m-2+2^{n-m}-1+$ $1+2^{m}-(m+2)\left(2^{n-m+1}-1\right)+3\left(3^{m-1}-2^{m}+1\right)\left(2^{n-m}\right)+2^{n-m}\left(2^{m}\right)-2$

Where $M$ is the union of none, one or more equivalence classes whose cardinality is equal to one in $G\left(Z^{*}(J)\right)$ and $M^{\prime}$ denotes the one either more equivalence classes having cardinality is equivalent to one in $G\left(Z^{*}(J)\right)$.

\section{Proof:}

Now let us consider $P_{2}=\left\{R S\left(x_{i} \cup M^{\prime}\right) \cup R S\left(X_{i} \cup M\right) \mid i=1,2 . . m\right\}$

To calculate the degree of vertices in this set, consider the following statements.

1. For each $i, R S\left(x_{i} \cup M^{\prime}\right) \cup R S\left(X_{i} \cup M\right)$ will not connected to $R S\left(x_{i}\right)$. Hence number of such elements to which $R S\left(x_{i}\right)$ connected to is $(m-1)\left(2^{n-m+1}-1\right)$.

2. For each $i, R S\left(x_{i} \cup M^{\prime}\right)$ is connected to all $R S\left(x_{i} \cup M^{\prime}\right) \cup R S\left(X_{i} \cup M\right)$ and $R S\left(X_{i} \cup M\right)$ is connected to all $R S\left(x_{i} \cup M^{\prime}\right) \cup R S\left(X_{i} \cup M\right)$. Therefore the total sum of such elements to which $R S\left(x_{i} \cup M^{\prime}\right) \cup R S\left(X_{i} \cup M\right)$ connected to is $\left(2^{n-m+1}-1\right)$. 
3. Evidently $R S\left(x_{i} \cup M^{\prime}\right) \cup R S\left(X_{i} \cup M\right)$ is connected to all the elements of the set $\left\{R S\left(Q_{j}\right) \mid Q_{j} \in P(Q)-\emptyset, Q=X_{m+1}, X_{m+2, \ldots} X_{n}\right\}$. Number of such elements to which $R S\left(x_{i} \cup M^{\prime}\right) \cup R S\left(X_{i} \cup M\right)$ connected to is $2^{n-m}-1$.

4. For each $i$, every elements in $R S\left(x_{i} \cup M^{\prime}\right) \cup R S\left(X_{i} \cup M\right)$ is connected to the set $\left\{R S\left(x_{1}, x_{2} \ldots x_{r}\right) \mid 1<r<m\right\}$. Number of such elements is given by $2^{m}-m-2$.

5. Similarly for each $i$, the set $P_{2}$ is connected to the single element set $R S\left(x_{1}, x_{2} \ldots x_{m}\right)$. Hence the number of such element is 1 .

6. For each $i$, every elements in $P_{2}$ is connected to the set $R S\left(x_{1}, x_{2} \ldots x_{r} \cup M^{\prime}\right)$ with $\left(2^{m}-\right.$ $(m+2))\left(2^{n-m}\right)$ elements and $P_{2}$ is connected to the set $R S\left(X_{1}, X_{2} \ldots X_{r} \cup M\right)$ with $\left(2^{m}-(m+2)\right)\left(2^{n-m}-1\right)$ elements and $P_{2}$ is connected to the set $R S\left(Q_{r} \cup M\right)$ where $Q_{r}=x_{r}$ or $X_{r}$ with $3\left(2^{n-m}\right)\left(3^{m-1}-2^{m}+1\right)$ elements.

7. For each $i$, every elements in $P_{2}$ is connected all the elements in the set $R S\left(x_{1}, x_{2} \ldots x_{m} \cup\right.$ $\left.M^{\prime}\right) \cup R S\left(X_{1}, X_{2} \ldots X_{m} \cup M\right) \cup R S\left(Q_{m} \cup M\right)$ with $2^{n-m}\left(2^{m}\right)-2$ elements.

8. Therefore for the total number of elements in $V\left(Z^{*}(J)\right)$ to which $R S\left(x_{i} \cup M^{\prime}\right) \cup$ $R S\left(X_{i} \cup M\right)$ is connected to is obtained by adding all the statements. Hence degree of $R S\left(x_{i} \cup M^{\prime}\right) \cup R S\left(X_{i} \cup M\right)$ is

$$
\begin{aligned}
& m\left(2^{n+1-m}-1\right)+2^{m}-m-2+2^{n-m}-1+1+2^{m}-(m+2)\left(2^{n-m+1}-1\right)+ \\
& 3\left(3^{m-1}-2^{m}+1\right)\left(2^{n-m}\right)+2^{n-m}\left(2^{m}\right)-2
\end{aligned}
$$

\section{Theorem 3.1.3}

The degree of the elements in the set $\left\{R S(Y) \mid Y \in M^{\prime}\right\}$ for $i=1,2, \ldots m$ is $\left(2^{m}+1\right) 2^{n-m}-$ $(m+2)\left(2^{n+1-m}-1\right)+2^{m}-m-2+2^{m}+3\left(2^{n-m}\right)\left(3^{m-1}-2^{m}+1\right)+2^{n-m}\left(2^{m}\right)-2$

\section{Proof:}

Let $P_{3}=\left\{R S(Y) \mid Y \in M^{\prime}\right\}$. A similar argument as in Theorem 3.1.2 is true for the elements of the set $\left\{R S(Y) \mid Y \in M^{\prime}\right\}$ and it is connected to all the elements in $V\left(Z^{*}(J)\right)$. Hence the total number of such elements in $P_{3}$ is $\left(2^{m}+1\right) 2^{n-m}-(m+2)\left(2^{n+1-m}-1\right)+2^{m}-m-2+2^{m}+$ $3\left(2^{n-m}\right)\left(3^{m-1}-2^{m}+1\right)+2^{n-m}\left(2^{m}\right)-2$.

Accurately the degree of each vertices in the set $\left\{R S(Y) \mid Y \in M^{\prime}\right\}$ is $2^{n-m} \cdot 3^{m}-3$.

\section{Theorem 3.1.4}

The degree of elements in $R S\left(x_{1}, x_{2} \ldots x_{r}\right)$ is $2^{n-m}\left(2^{m}\right)-2^{m-1}-2+\left\{\left(\frac{m(m-1)}{2}-1\right)+\right.$ $\left.\left(\frac{m(m-1)(m-2)}{2}-1.2+2.3+\cdots(m-2)(m-1)\right)+\cdots+1-2+(|A|-(*+* *+* * *))\right\}$

Where $|A|=2^{n-m}\left(2^{m}\right)-2$ 
$*=\left\{\left[\frac{m(m-1)}{2}\right] .\left[(m-2) C_{0}+(m-2) C_{1}+\cdots+(m-2) C_{m-3}\right]+\left[\frac{m(m-1)(m-2)}{2}-1.2+\right.\right.$ $2.3+\cdots(m-2)(m-1)] \cdot\left[(m-3) C_{0}+(m-3) C_{1}+\cdots+(m-3) C_{m-4}\right]+\cdots+$ 1. $\left.\left[m(m(m-1)) \cdot\left(2^{n-m}-1\right)\right]\right\}$

**= $\left\{\left[\frac{m(m-1)}{2}\right] \cdot\left[(m-2) C_{0}+(m-2) C_{1}+\cdots+(m-2) C_{m-3}\right]+\left[\frac{m(m-1)(m-2)}{2}-1.2+\right.\right.$ $2.3+\cdots(m-2)(m-1)] \cdot\left[(m-3) C_{0}+(m-3) C_{1}+\cdots+(m-3) C_{m-4}\right]+\cdots+$ 1. $\left.\left[m(m(m-1)) \cdot\left(2^{n-m}\right)\right]\right\}$

$$
* * *=\left\{\left[\frac{m(m-1)}{2}\right]\left[\sum_{k=2}^{m-1} \sum_{i=1}^{k-1} k C_{i}\right]+\left[\frac{m(m-1)(m-2)}{2}-1.2+2.3+\cdots(m-2)(m-1)\right]+\right.
$$
$\left.\left[\sum_{k=3}^{m-1} \sum_{i=1}^{k-1} k C_{i}\right]+. .+1\right\} 2^{n-m}$

\section{Proof:}

Consider the set $P_{4}=R S\left(x_{1}, x_{2} \ldots x_{r}\right)$ where $1<r<m$.

When $r=2$, An element $R S(Z)$ will be connected to $R S\left(x_{1}, x_{2}\right)$ precisely if $R S(Z) \notin$ $R S\left(x_{1}, x_{2}\right) \nabla J$ and $R S\left(x_{1}, x_{2}\right) \notin R S(Z) \nabla \mathrm{J}$. The degree of $R S\left(x_{1}, x_{2}\right)$ is acquired by considering those vertices of $R S(Z)$ connected to $R S\left(x_{1}, x_{2}\right)$. Hence $R S\left(x_{1}, x_{2}\right)$ is connected to $P_{1}$ with ( $m-$ 2) elements where $i \neq 1,2$ and it is connected to $P_{2}$ with $2 m\left(2^{n-m}\right)-m$ elements and $R S\left(x_{1}, x_{2}\right)$ is connected to $P_{3}$ with $2^{n-m}-1$ elements.

When $r=3, R S\left(x_{1}, x_{2}, x_{3}\right)$ is connected to $P_{1}$ with $(m-2)$ elements where $i \neq 1,2,3$ and it is connected to $P_{2}$ with $2 m\left(2^{n-m}\right)-m$ elements and $R S\left(x_{1}, x_{2}, x_{3}\right)$ is connected to $P_{3}$ with $2^{n-m}-1$ elements. Clearly it is true for $r=m-1$.

The degree of elements in $P_{4}$ is $2^{n-m}\left(2^{m}\right)-2^{m-1}-2+\left\{\left(\frac{m(m-1)}{2}-1\right)+\left(\frac{m(m-1)(m-2)}{2}-\right.\right.$ $1.2+2.3+\cdots(m-2)(m-1))+\cdots+1-2+(|A|-(*+* *+* * *))\}$

\section{Theorem 3.1.5:}

The degree of $R S\left(x_{1}, x_{2}, \ldots x_{m}\right)$ is $2^{n-m}\left[2 m+2^{m}-(m+2)+3\left(3^{m-1}-2^{m}+1\right)\right]-m$

\section{Proof:}

Now we consider the set $P_{5}=R S\left(x_{1}, x_{2}, \ldots x_{m}\right)$ for every $x_{i} \in B$. A vertex $R S(X)$ will be connected to $R S\left(x_{i}\right)$ for $i=1,2, \ldots m$ if and only if $R S(X) \notin R S\left(x_{i}\right) \nabla J$ and $R S\left(x_{i}\right) \notin R S(X) \nabla \mathrm{J}$. The degree of $P_{5}$ (single element) is achieved by taking into account of those vertices to which $R S(X)$ which are adjacent to $R S\left(x_{1}, x_{2}, \ldots x_{m}\right)$. Also $R S\left(x_{1}, x_{2}, \ldots x_{m}\right)$ is not connected to the set 
$P(B)$, where $B=\left\{x_{1}, x_{2}, \ldots x_{m}\right\}$. Hence the degree of each elements in the set $R S\left(x_{1}, x_{2}, \ldots x_{m}\right)$ is $2^{n-m}\left[2 m+2^{m}-(m+2)+3\left(3^{m-1}-2^{m}+1\right)\right]-m$.

\section{Theorem 3.1.6:}

The degree of $\left\{R S\left(x_{1}, x_{2}, \ldots x_{r} \cup M^{\prime}\right) \mid 1<r<m\right\}$ is $2^{n-m}\left[2 m+2^{m}+1+3\left(3^{m-1}-\right.\right.$ $\left.\left.2^{m}+1\right)\right]+\left[2^{m}-(m+2)\right]\left(2^{n-m+1}-1\right)-8$

\section{Proof:}

Let us consider $\left\{R S\left(x_{1}, x_{2}, \ldots x_{r} \cup M^{\prime}\right) \mid 1<r<m\right\}$.

Observe that the set $\left\{R S\left(x_{1}, x_{2}, \ldots x_{r} \cup M^{\prime}\right) \mid 1<r<m\right\}$ will not be connected to the elements in this set $\left(x_{1}, x_{2}, \ldots x_{r}\right)$. Also $R S\left(x_{1}, x_{2}, \ldots x_{r} \cup M^{\prime}\right) \notin R S\left(x_{i} \cup M^{\prime}\right) \cup R S\left(X_{i} \cup M\right) \nabla J$ and $\left.R S\left(x_{i} \cup M^{\prime}\right) \cup R S\left(X_{i} \cup M\right)\right) \notin R S\left(x_{1}, x_{2}, \ldots x_{r} \cup M^{\prime}\right) \nabla \mathrm{J}$.

Hence it is adjacent to all the elements of the set $P_{3}$ and $P_{5}$. Therefore the degree of $\left\{R S\left(x_{1}, x_{2}, \ldots x_{r} \cup M^{\prime}\right) \mid 1<r<m\right\} \quad$ is $2^{n-m}\left[2 m+2^{m}+1+3\left(3^{m-1}-2^{m}+1\right)\right]+\left[2^{m}-\right.$ $(m+2)]\left(2^{n-m+1}-1\right)-8$

\section{Corollary 1:}

The degree of $\left\{R S\left(X_{1}, X_{2}, \ldots X_{r} \cup M\right) \mid 1<r<m\right\}$ is $2^{n-m}\left[2 m+2^{m}+1+3\left(3^{m-1}-2^{m}+\right.\right.$ 1) $]+\left[2^{m}-(m+2)\right]\left(2^{n-m+1}-1\right)-8$

\section{Proof:}

The proof is follows from Theorem 3.1.6. Consider $\left\{R S\left(X_{1}, X_{2}, \ldots X_{r} \cup M\right) \mid 1<r<m\right\}$ where $\left|X_{i}\right|>1$

Hence the degree of $\left\{R S\left(X_{1}, X_{2}, \ldots X_{r} \cup M\right) \mid 1<r<m\right\}$ is $2^{n-m}\left[2 m+2^{m}+1+3\left(3^{m-1}-\right.\right.$ $\left.\left.2^{m}+1\right)\right]+\left[2^{m}-(m+2)\right]\left(2^{n-m+1}-1\right)-8$

\section{Corollary 2:}

The degree of $R S\left(Q_{r} \cup M\right)$ is $2^{n-m}\left[2 m+2^{m}+1+3\left(3^{m-1}-2^{m}+1\right)\right]+\left[2^{m}-(m+\right.$ 2)] $\left(2^{n-m+1}-1\right)-8$

\section{Proof:}

The proof is similar to Theorem 3.1.6. The degree of $R S\left(Q_{r} \cup M\right), Q_{r}=\left\{\left(Z_{1}, Z_{2}, \ldots Z_{r}\right) \mid Z_{i}=\right.$ $y_{i}$ or $\left.Y_{i}\right\} \quad$ and $i=1,2, \ldots m$ is $2^{n-m}\left[2 m+2^{m}+1+3\left(3^{m-1}-2^{m}+1\right)\right]+\left[2^{m}-(m+\right.$ $2)]\left(2^{n-m+1}-1\right)-8$

\section{Theorem 3.1.7:}


The degree of $R S\left(x_{1}, x_{2}, \ldots x_{m} \cup M^{\prime}\right)$ is $2^{n-m}\left[2^{m+1}+m-2+3\left(3^{m-1}-2^{m}+1\right)\right]-$ $(m+3)$

\section{Proof:}

Let us take the set $R S\left(x_{1}, x_{2}, \ldots x_{m} \cup M^{\prime}\right)$ note that $R S\left(x_{1}, x_{2}, \ldots x_{m} \cup M^{\prime}\right)$ is not connected to the elements of $P(B)$. But $R S\left(x_{1}, x_{2}, \ldots x_{m} \cup M^{\prime}\right)$ is connected to the elements in $R S\left(x_{1}, x_{2}, \ldots x_{r} \cup M^{\prime}\right) \cup R S\left(X_{1}, X_{2}, \ldots X_{r} \cup M\right) \cup R S\left(Q_{r} \cup M\right)$ where $1<r<m$ and also it is connected to $P_{2}$ and $P_{3}$. Hence the degree of $R S\left(x_{1}, x_{2}, \ldots x_{m} \cup M^{\prime}\right)$ is $2^{n-m}\left[2^{m+1}+m-2+\right.$ $\left.3\left(3^{m-1}-2^{m}+1\right)\right]-(m+3)$

\section{Corollary 3:}

The degree of $R S\left(X_{1}, X_{2}, \ldots X_{m} \cup M\right)$ is $2^{n-m}\left[2^{m+1}+m-2+3\left(3^{m-1}-2^{m}+1\right)\right]-(m+$ 3)

\section{Proof:}

The proof is obvious from Theorem 3.1.7.

\section{Corollary 2:}

The degree of $R S\left(Q_{m} \cup M\right)$ is $2^{n-m}\left[2^{m+1}+m-2+3\left(3^{m-1}-2^{m}+1\right)\right]-(m+3)$

\section{Proof:}

The proof is similar to Theorem 3.1.7.

\subsection{Partition Graph}

In this section we define a partition on $V\left(Z^{*}(J)\right)$. A partition graph is defined using this partition which is based on the degree's of vertices in $G\left(Z^{*}(J)\right)$. The objective of this partition graph is to make the study of $G\left(Z^{*}(J)\right)$ simpler. Because all the vertices in one partition will have the same degree and they behave similarly.

\section{Definition 3.2.1:}

The partition graph $P\left(Z^{*}(J)\right)$ is a graph whose vertices are the partitions on $V\left(Z^{*}(J)\right)$. Hence the vertices of $P\left(Z^{*}(J)\right)$ is the set $\left\{P_{1}, P_{2}, P_{3}, P_{4}, P_{5}, P_{6}, P_{7}\right\}$, where

$$
\begin{aligned}
& P_{1}=R S\left(x_{i}\right) \\
& P_{2}=R S\left(x_{i} \cup M^{\prime}\right) \cup R S\left(X_{i} \cup M\right) \\
& P_{3}=\left\{R S(Y) \mid Y \in M^{\prime}\right\} \\
& P_{4}=R S\left(x_{1}, x_{2}, \ldots x_{r}\right)
\end{aligned}
$$


$P_{5}=R S\left(x_{1}, x_{2}, \ldots x_{m}\right)$

$P_{6}=R S\left(x_{1}, x_{2}, \ldots x_{r} \cup M^{\prime}\right) \cup R S\left(X_{1}, X_{2}, \ldots X_{r} \cup M\right) \cup R S\left(Q_{r} \cup M\right)$

$P_{7}=R S\left(x_{1}, x_{2}, \ldots x_{m} \cup M^{\prime}\right) \cup R S\left(X_{1}, X_{2}, \ldots X_{m} \cup M\right) \cup R S\left(Q_{m} \cup M\right)$

Two vertices $P_{i}$ and $P_{j}$ in the partition graph are connected by an edge if the elements in $P_{i}$ are adjacent to any of the elements in $P_{j}$ by an edge in $G\left(Z^{*}(J)\right)$.

\section{Note:}

It is very important to notice that the partition graph of $G\left(Z^{*}(J)\right)$ always has 7 vertices and the number of elements in each of the partition will vary as $m$ and $n$ varies. Also note that when $n=$ $m, M^{\prime}=\left\{R S(Y) \mid Y \in P\left(X_{m+1}, X_{m+2}, \ldots X_{n}\right)\right\}=\emptyset$, therefore $P_{3}=\emptyset$. Hence when $n=m$, the number of vertices in the partition graph of $G\left(Z^{*}(J)\right)$ has only 6 vertices.

The elements of $P_{i}$ for all $i, i \neq 4$ will form a complete graph. When $i=4$, the elements of $P_{4}$ will form a complete graph for $m=3$ and for all $n$. It is easy to verify that it need not be true for $m>3$.

The following figure 3 represents the partition graph of $G\left(Z^{*}(J)\right)$ for $n \neq m$

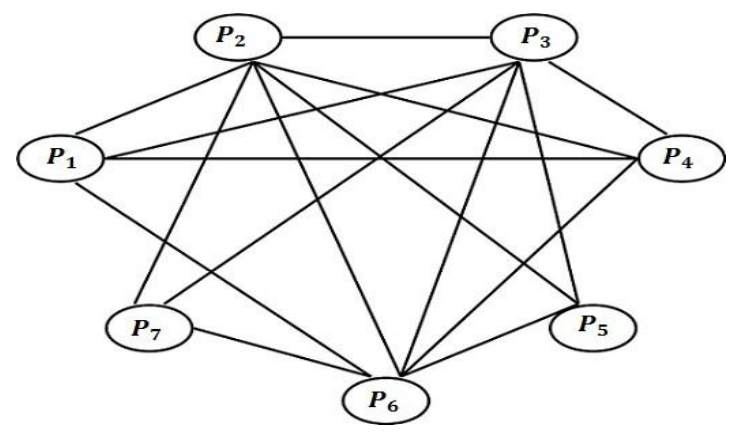

Figure 3: Partition Graph for $\mathrm{n} \neq \mathrm{m}$

When $n=m$ the corresponding partition graph of $G\left(Z^{*}(J)\right)$ is given in figure 4

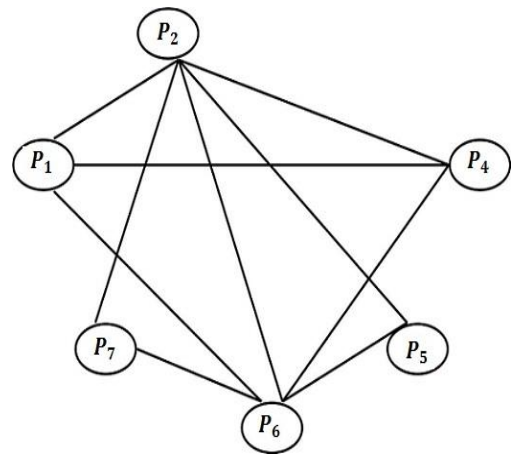

Figure 4: Partition Graph for $n=m$ 
Now the following table gives the elements of partition graph and the cardinality of each partition for all values of $m$ and $n$.

Table 1: Partitions and Cardinalities of $\mathrm{G}\left(\mathrm{Z}^{*}(\mathrm{~J})\right)$

\begin{tabular}{|c|c|c|}
\hline $\begin{array}{c}\text { Partitions } \\
\left(\boldsymbol{P}_{\boldsymbol{i}}\right)\end{array}$ & Elements & Cardinality \\
\hline$P_{1}$ & $R S\left(x_{i}\right)$ & $m$ \\
\hline$P_{2}$ & $R S\left(x_{i} \cup M^{\prime}\right) \cup R S\left(X_{i} \cup M\right)$ & $2 m\left(2^{n-m}\right)-m$ \\
\hline$P_{3}$ & $\left\{R S(Y) \mid Y \in M^{\prime}\right\}$ & $2^{n-m}-1$ \\
\hline$P_{4}$ & $R S\left(x_{1}, x_{2}, \ldots x_{r}\right)$ & $2^{m}-(m+2)$ \\
\hline$P_{5}$ & $R S\left(x_{1}, x_{2}, \ldots x_{m}\right)$ & 1 \\
\hline$P_{6}$ & $R S\left(x_{1}, x_{2}, \ldots x_{r} \cup M^{\prime}\right) \cup R S\left(X_{1}, X_{2}, \ldots X_{r} \cup M\right) \cup R S\left(Q_{r} \cup M\right)$ & $2^{m}-(m+2)\left(2^{n-m+1}-1\right.$ \\
& & $+3\left(2^{n-m}\right)\left(3^{m-1}-2^{m}+1\right)$ \\
\hline$P_{7}$ & $R S\left(x_{1}, x_{2}, \ldots x_{m} \cup M^{\prime}\right) \cup R S\left(X_{1}, X_{2}, \ldots X_{m} \cup M\right) \cup R S\left(Q_{m} \cup M\right)$ & $2^{n-m}\left(2^{m}\right)-2$ \\
\hline
\end{tabular}

\section{Examples}

\section{Example 3.2.1}

From Illustration 1 in section 2, we obtain the elements in each partition of $G\left(Z^{*}(J)\right)$ using table 1 .

Table 2: Partitions and Cardinalities of $\mathrm{G}\left(\mathrm{Z}^{*}(\mathrm{~J})\right)$ for $\mathrm{n}=3 \& m=2$

\begin{tabular}{|c|c|c|}
\hline $\begin{array}{c}\text { Partitions } \\
\left(P_{i}\right)\end{array}$ & Elements & Cardinality \\
\hline$P_{1}$ & $R S\left(x_{1}\right), R S\left(x_{2}\right)$ & 2 \\
\hline$P_{2}$ & $\begin{array}{l}R S\left(x_{1} \cup X_{3}\right), R S\left(x_{2} \cup X_{3}\right), R S\left(X_{1}\right) \\
R S\left(X_{2}\right), R S\left(X_{1} \cup X_{3}\right), R S\left(X_{2} \cup X_{3}\right)\end{array}$ & 6 \\
\hline$P_{3}$ & $R S\left(X_{3}\right)$ & 1 \\
\hline$P_{4}$ & $\varnothing$ & 0 \\
\hline$P_{5}$ & $R S\left(x_{1} x_{2}\right)$ & 1 \\
\hline$P_{6}$ & $\emptyset$ & 0 \\
\hline$P_{7}$ & $\begin{array}{c}R S\left(X_{1} \cup X_{2}\right), R S\left(x_{1} \cup X_{2}\right), R S\left(X_{1} \cup x_{2}\right) \\
R S\left(x_{1} \cup X_{2} \cup X_{3}\right), R S\left(X_{1} \cup x_{2} \cup X_{3}\right) \\
R S\left(x_{1} \cup x_{2} \cup X_{3}\right)\end{array}$ & 6 \\
\hline
\end{tabular}

The partition graph for the above mentioned Example 3.2.1 is given below

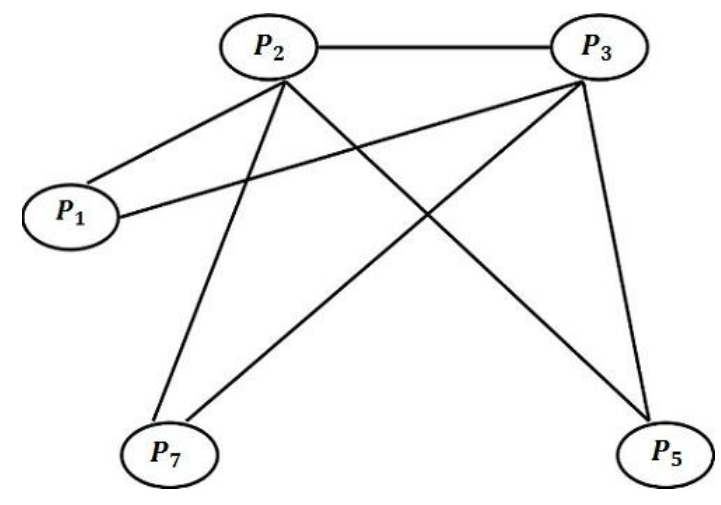

Figure 5: Partition Graph for $\mathrm{n}=3$ and $\mathrm{m}=2$ 


\section{Example 3.2.2}

From Illustration 2 in section 2, we examine the elements in each partition of $G\left(Z^{*}(J)\right)$ using table 3.

Table 3: Partitions and Cardinalities of $G\left(Z^{*}(J)\right)$ for $n=m=3$

\begin{tabular}{|c|c|c|}
\hline $\begin{array}{c}\text { Partitions } \\
\left(\boldsymbol{P}_{\boldsymbol{i}}\right)\end{array}$ & Elements & Cardinality \\
\hline$P_{1}$ & $R S\left(x_{1}\right), R S\left(x_{2}\right), R S\left(x_{3}\right)$ & 3 \\
\hline$P_{2}$ & $R S\left(X_{1}\right), R S\left(X_{2}\right), R S\left(X_{3}\right)$ & 3 \\
\hline$P_{3}$ & $\emptyset$ & 3 \\
\hline$P_{4}$ & $R S\left(x_{1} \cup x_{2}\right), R S\left(x_{1} \cup x_{3}\right), R S\left(x_{2} \cup x_{3}\right)$ & 1 \\
\hline$P_{5}$ & $R S\left(x_{1} \cup x_{2} \cup x_{3}\right)$ & \\
\hline & $R S\left(X_{1} \cup X_{2}\right), R S\left(X_{1} \cup X_{3}\right), R S\left(X_{2} \cup X_{3}\right)$ & \\
$P_{6}$ & $R S\left(x_{1} \cup X_{2}\right), R S\left(x_{1} \cup X_{2}\right), R S\left(x_{1} \cup X_{3}\right)$ & \\
& $R S\left(X_{1} \cup x_{3}\right), R S\left(x_{2} \cup X_{3}\right), R S\left(X_{2} \cup x_{3}\right)$ & \\
\hline$P_{7}$ & $R S\left(x_{1} \cup X_{2} \cup X_{3}\right), R S\left(X_{1} \cup x_{2} \cup X_{3}\right), R S\left(X_{1} \cup X_{2} \cup x_{3}\right)$ & 6 \\
\hline
\end{tabular}

The partition graph for t Example 3.2.2 is given below

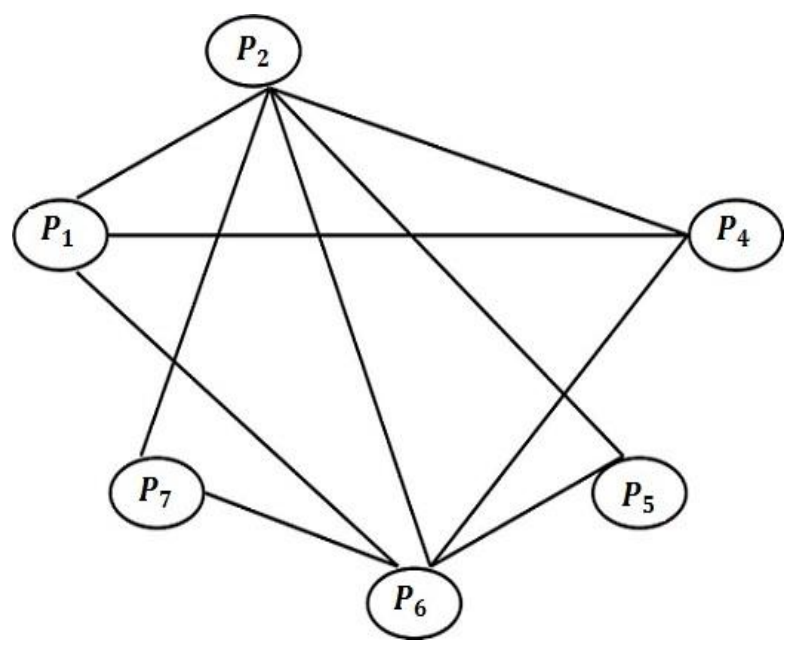

Figure 6: Partition Graph for $n=m=3$

\subsection{Wiener Index of $G\left(Z^{*}(J)\right)$ using Partition Graph}

In this section we calculate the wiener index of $G\left(Z^{*}(J)\right)$ using Partition Graph $P\left(Z^{*}(J)\right)$.

\section{Definition 3.3.1:}

Let $G\left(Z^{*}(J)\right)$ be a Rough co-zero divisor graph. The wiener index $W\left(Z^{*}(J)\right)$ of $G\left(Z^{*}(J)\right)$ defined by $W\left(Z^{*}(J)\right)=\sum_{R S\left(x_{i}\right), R S\left(x_{j}\right) \in V\left(Z^{*}(J)\right)} d\left(R S\left(x_{i}\right), R S\left(x_{j}\right)\right)$, where $d\left(R S\left(x_{i}\right), R S\left(x_{j}\right)\right)$ is the distance between the elements $R S\left(x_{i}\right)$ and $R S\left(x_{j}\right)$ in $G\left(Z^{*}(J)\right)$. 
To make the calculation simpler, if $d\left(R S\left(x_{i}\right), R S\left(x_{j}\right)\right)$ is taken for calculation then $d\left(R S\left(x_{j}\right), R S\left(x_{i}\right)\right)$ is not taken into account as both are one and the same.

\section{Connectedness between the Partitions}

In this section we compute the distances from one partition to every other partition. The main advantage of the partition graph is that all the vertices of one partition will behave similarly. Hence the distance between the vertices of $G\left(Z^{*}(J)\right)$ can be obtained by calculating distance between the partition in $P\left(Z^{*}(J)\right)$. Therefore we calculate the distance from $P_{1}$ to $P_{2}, P_{3}, P_{4}, P_{5}, P_{6}$ and $P_{7}$ the distance from $P_{2}$ to $P_{3}, P_{4}, P_{5}, P_{6}$ and $P_{7} \ldots$ and the distance from $P_{6}$ to $P_{7}$. Following propositions will detail the distance from one partition to another.

\section{Proposition 3.3.1:}

The distance between the vertices of $P_{1}$ to the vertices of $P_{2}$ is given by

$$
\begin{aligned}
\left|P_{1}\right|\left\{1 .\left(\left|P_{2}\right|-2^{n+1-m}+1\right)+2 \cdot\left(-2^{n-m+1}+1\right)\right\} \\
=m\left\{1 \cdot\left(2 m\left(2^{n-m}\right)-m-2^{n+1-m}+1\right)+2 \cdot\left(1-2^{n-m+1}\right)\right\}
\end{aligned}
$$

Where $P_{1}=R S\left(x_{i}\right) ; P_{2}=R S\left(x_{i} \cup M^{\prime}\right) \cup R S\left(X_{i} \cup M\right)$

\section{Proof:}

For each $i=1,2, . . m R S\left(x_{i}\right)$ is connected to $R S\left(x_{i} \cup M^{\prime}\right) \cup R S\left(X_{i} \cup M\right)$ for $i \neq j$ and hence the distance is one. Therefore we have (1). $\left|P_{1}\right|\left(\left|P_{2}\right|-\left(2^{n-m}-1\right)-\left(\left(2^{n-m}\right)\right)\right.$

For $i=j$ the distance between $R S\left(x_{i}\right)$ to $R S\left(x_{i} \cup M^{\prime}\right) \cup R S\left(X_{i} \cup M\right)$ is 2. Thus we have (2). $\left|P_{1}\right|\left(-\left(2^{n-m}-1\right)-\left(2^{n-m}\right)\right)$.

Therefore the sum of such distance is given by $\left|P_{1}\right|\left\{1 .\left(\left|P_{2}\right|-2^{n+1-m}+1\right)+2 \cdot\left(-2^{n-m+1}+\right.\right.$ $1)\}=m\left\{1 \cdot\left(2 m\left(2^{n-m}\right)-m-2^{n+1-m}+1\right)+2 \cdot\left(1-2^{n-m+1}\right)\right\}$

\section{Proposition 3.3.2:}

The distance between the vertices of $P_{1}$ to the vertices of $P_{3}$ is given by $1 .\left(\left|P_{1}\right| .\left|P_{3}\right|\right)=$ 1. $\left(m .\left(2^{n-m}-1\right)\right)$, where $P_{1}=R S\left(x_{i}\right)$ and $P_{3}=\left\{R S(Y) \mid Y \in M^{\prime}\right\}$

\section{Proof:}

Since for $i=1,2 \ldots m$ each element in the partition $P_{1}$ is connected to each element in $P_{3}$. Hence the distance is $1 .\left(\left|P_{1}\right| \cdot\left|P_{3}\right|\right)=1 \cdot\left(m \cdot\left(2^{n-m}-1\right)\right)$

\section{Proposition 3.3.3:}

The distance between the vertices of $P_{1}$ to the vertices of $P_{4}$ is given by 
$\left|P_{1}\right|\left\{1 .\left(\left|P_{4}\right|-\left(2^{m-1}-2\right)\right)+2 .\left(\left(2^{m-1}-2\right)\right\}=m\left\{1 .\left(\left(2^{m}-(m+2)\right)-\left(2^{m-1}-2\right)\right)+\right.\right.$ 2. $\left.\left(2^{m-1}-2\right)\right\}$ Where $P_{1}=R S\left(x_{i}\right)$ and $P_{4}=R S\left(x_{1}, x_{2}, \ldots x_{r}\right)$

\section{Proof:}

Considering the elements in $P_{1}$ there exist $\left(2^{m}-(m+2)-2^{m-1}+2\right)$ elements are connected to $P_{4}$ with distance 1 and $2^{m-1}+2$ elements are connected with distance 2 .

Thus the distance from $P_{1}$ to $P_{4}$ is $\left|P_{1}\right|\left\{1 .\left(\left|P_{4}\right|-\left(2^{m-1}-2\right)\right)+2 \cdot\left(\left(2^{m-1}-2\right)\right\}=\right.$ $m\left\{1 \cdot\left(\left(2^{m}-(m+2)\right)-\left(2^{m-1}-2\right)\right)+2 \cdot\left(2^{m-1}-2\right)\right\}$

\section{Proposition 3.3.4:}

The distance between the vertices of $P_{1}$ to the vertices of $P_{5}$ is given by $2 .\left(\left|P_{1}\right| .\left|P_{5}\right|\right)=2 . m$

Where $P_{1}=R S\left(x_{i}\right)$ and $P_{4}=R S\left(x_{1}, x_{2}, \ldots x_{m}\right)$

\section{Proof:}

Being $i=1,2 \ldots m$ none of the elements in $P_{1}$ is connected to $P_{5}$ with distance 1 .

Hence 2. $\left(\left|P_{1}\right| .\left|P_{5}\right|\right)=2 m$. Which means that every elements in $P_{1}$ is not connected to $P_{5}$.

\section{Proposition 3.3.5:}

The distance between the vertices of $P_{1}$ to the vertices of $P_{6}$ is given by

$\left|P_{1}\right|\left\{1 .\left[(m-1) C_{r}\left(2^{-(-n+m)}-1\right)+\left(2^{-(m-n)}\right)\left((m-1) C_{r}+\sum_{r=2}^{m-1}\left((m-1) C_{1}+(m-\right.\right.\right.\right.$ 1) $\left.\left.\left.C_{2}+\cdots+(m-1) C_{r-1}\right)\right]\right)+2 \cdot\left[\left|P_{6}\right|-(m-1) C_{r}\left(2^{n-m}-1\right)+(m-1) C_{r}\left(2^{n-m}\right)+\right.$ $\left.\left.\left(2^{n-m}\right) \sum_{r=2}^{m-1}\left((m-1) C_{1}+(m-1) C_{2}+\cdots+(m-1) C_{r-1}\right)\right]\right\}=m\left\{1 .\left[(m-1) C_{r}\left(2^{n-m}-\right.\right.\right.$ $\left.1)+(m-1) C_{r}\left(2^{n-m}\right)+\left(2^{n-m}\right) \sum_{r=2}^{m-1}\left((m-1) C_{1}+(m-1) C_{2}+\cdots+(m-1) C_{r-1}\right)\right]+$ 2. $\left[2^{m}-(2+m)\left(2^{n+1-m}-1\right)+3\left(2^{n-m}\right)\left(3^{m-1}-2^{m}+1\right)-(m-1) C_{r}\left(2^{n-m}-1\right)+(m-\right.$ 1) $\left.\left.C_{r}\left(2^{n-m}\right)+\left(2^{n-m}\right) \sum_{r=2}^{m-1}\left((m-1) C_{1}+(m-1) C_{2}+\cdots+(m-1) C_{r-1}\right)\right]\right\}$

Where $P_{1}=R S\left(x_{i}\right)$ and $P_{6}=R S\left(x_{1}, x_{2}, \ldots x_{r} \cup M^{\prime}\right) \cup R S\left(X_{1}, X_{2}, \ldots X_{r} \cup M\right) \cup R S\left(Q_{r} \cup M\right)$

\section{Proof:}

In view of partition $P_{6}$ has $R S\left(x_{1}, x_{2}, \ldots x_{r} \cup M^{\prime}\right) \cup R S\left(X_{1}, X_{2}, \ldots X_{r} \cup M\right) \cup R S\left(Q_{r} \cup M\right)$ elements with cardinality $2^{m}-(m+2)\left(2^{n-m+1}-1\right)+3\left(2^{n-m}\right)\left(3^{m-1}-2^{m}+1\right)$.

Since $R S\left(x_{i}\right)$ is connected to $R S\left(x_{1}, x_{2}, \ldots x_{r} \cup M^{\prime}\right)$ accompanying $2^{m}-(m+2)\left(2^{n-m}-\right.$ 1) with distance $1, R S\left(x_{i}\right)$ is connected to $R S\left(X_{1}, X_{2}, \ldots X_{r} \cup M\right)$ accompanying $2^{m}-(m+$ 2) $\left(2^{n-m}\right)$ with distance 1 and $R S\left(x_{i}\right)$ is connected to $R S\left(Q_{r} \cup M\right)$ accompanying 
$\left(2^{n-m}\right)\left(3^{m-1}-2^{m}+1\right)$ with distance 1 . Remaining elements in $P_{6}$ are connected $R S\left(x_{i}\right)$ with distance 2 .

On that account we have the distance from $P_{1}$ to $P_{6}$ is

$\left|P_{1}\right|\left\{1 \cdot\left[(m-1) C_{r}\left(2^{-(-n+m)}-1\right)+\left(2^{-(m-n)}\right)\left((m-1) C_{r}+\sum_{r=2}^{m-1}\left((m-1) C_{1}+(m-\right.\right.\right.\right.$ 1) $\left.\left.\left.C_{2}+\cdots+(m-1) C_{r-1}\right)\right]\right)+2 \cdot\left[\left|P_{6}\right|-(m-1) C_{r}\left(2^{n-m}-1\right)+(m-1) C_{r}\left(2^{n-m}\right)+\right.$ $\left.\left.\left(2^{n-m}\right) \sum_{r=2}^{m-1}\left((m-1) C_{1}+(m-1) C_{2}+\cdots+(m-1) C_{r-1}\right)\right]\right\}=m\left\{1 \cdot\left[(m-1) C_{r}\left(2^{n-m}-\right.\right.\right.$ $\left.1)+(m-1) C_{r}\left(2^{n-m}\right)+\left(2^{n-m}\right) \sum_{r=2}^{m-1}\left((m-1) C_{1}+(m-1) C_{2}+\cdots+(m-1) C_{r-1}\right)\right]+$ 2. $\left[2^{m}-(2+m)\left(2^{n+1-m}-1\right)+3\left(2^{n-m}\right)\left(3^{m-1}-2^{m}+1\right)-(m-1) C_{r}\left(2^{n-m}-1\right)+(m-\right.$ 1) $\left.\left.C_{r}\left(2^{n-m}\right)+\left(2^{n-m}\right) \sum_{r=2}^{m-1}\left((m-1) C_{1}+(m-1) C_{2}+\cdots+(m-1) C_{r-1}\right)\right]\right\}$

\section{Proposition 3.3.6:}

The distance between the vertices of $P_{1}$ to the vertices of $P_{7}$ is given by

$$
\text { 2. }\left(\left|P_{1}\right| \cdot\left|P_{7}\right|\right)=2 \cdot\left(m \cdot 2^{n-m}\left(2^{m}\right)-2\right) \text {, }
$$

Where $P_{1}=R S\left(x_{i}\right)$ and $P_{6}=R S\left(x_{1}, x_{2}, \ldots x_{m} \cup M^{\prime}\right) \cup R S\left(X_{1}, X_{2}, \ldots X_{m} \cup M\right) \cup R S\left(Q_{m} \cup\right.$ M)

\section{Proof:}

Being $i=1,2 \ldots m$ none of the elements in $P_{1}$ is connected to $P_{7}$ with distance 1 . Therefore it is connected through another element so the distance 2 .

Hence 2. $\left(\left|P_{1}\right| .\left|P_{7}\right|\right)=2 .\left(m \cdot 2^{n-m}\left(2^{m}\right)-2\right)$.

\section{Proposition 3.3.7:}

The distance between the vertices of $P_{2}$ to the vertices of $P_{3}$ is given by $1 .\left(\left|P_{2}\right| .\left|P_{3}\right|\right)=$ 1. $\left(2^{n-m}(2 m+1)-(m+1)\right)$

Where $P_{2}=R S\left(x_{i} \cup M^{\prime}\right) \cup R S\left(X_{i} \cup M\right) ; P_{3}=\left\{R S(Y) \mid Y \in M^{\prime}\right\}$

\section{Proof:}

In $P_{2}$ we posses $m$ equivalence classes and $P_{3}$ have $n-m$ equivalence classes. By using the definition of Rough co-zero divisor graph every elements in $P_{2}$ is connected to every elements in $P_{3}$. Hence $P_{2}$ is adjacent to $P_{3}$ with distance 1 .

Thus we have 1. $\left(\left|P_{2}\right| \cdot\left|P_{3}\right|\right)=1 \cdot\left(2^{n-m}(2 m+1)-(m+1)\right)$. 
In a similar manner by the definition of partition graph, partition $P_{2}$ is connected to $P_{4}, P_{5}, P_{6}$ and $P_{7}$ accompanied by distance 1 .

\section{Proposition 3.3.8:}

The distance between the vertices of $P_{2}$ to the vertices of $P_{4}$ is given by $1 .\left(\left|P_{2}\right| \cdot\left|P_{4}\right|\right)=$ 1. $\left[\left(2 m\left(2^{n-m}\right)-m\right)\left(2^{m}-(m+2)\right)\right]$

Where $P_{2}=R S\left(x_{i} \cup M^{\prime}\right) \cup R S\left(X_{i} \cup M\right) ; P_{4}=R S\left(x_{1}, x_{2} \ldots x_{r}\right)$

\section{Proof:}

Can be proved by direct verification.

\section{Proposition 3.3.9:}

The distance between the vertices of $P_{2}$ to the vertices of $P_{5}$ is given by $1 .\left(\left|P_{2}\right| \cdot\left|P_{5}\right|\right)=$ 1. $\left.\left(2 m\left(2^{n-m}\right)-m\right)\right)$ where $P_{2}=R S\left(x_{i} \cup M^{\prime}\right) \cup R S\left(X_{i} \cup M\right) ; P_{5}=R S\left(x_{1}, x_{2} \ldots x_{m}\right)$

\section{Proof:}

Can be proved by direct verification.

\section{Proposition 3.3.10:}

The distance between the vertices of $P_{2}$ to the vertices of $P_{6}$ is given by $1 .\left(\left|P_{2}\right| .\left|P_{6}\right|\right)=$ 1. $\left.\left[\left(2 m\left(2^{n-m}\right)-m\right)\right) \cdot\left(2^{m}-(m+2)\left(2^{n-m+1}-1\right)+3\left(2^{n-m}\right)\left(3^{m-1}-2^{m}+1\right)\right)\right]$

Where $P_{2}=R S\left(x_{i} \cup M^{\prime}\right) \cup R S\left(X_{i} \cup M\right) ; \quad P_{6}=R S\left(x_{1}, x_{2} \ldots x_{r} \cup M^{\prime}\right) \cup R S\left(X_{1}, X_{2} \ldots X_{r} \cup\right.$ $M) \cup R S\left(Q_{r} \cup M\right)$

\section{Proof:}

Can be proved by direct verification.

\section{Proposition 3.3.11:}

The distance between the vertices of $P_{2}$ to the vertices of $P_{7}$ is given by $1 .\left(\left|P_{2}\right| \cdot\left|P_{7}\right|\right)=$ 1. $\left.\left[\left(2 m\left(2^{n-m}\right)-m\right)\right) \cdot\left(2^{n-m}\left(2^{m}\right)-2\right)\right]$

Where $P_{2}=R S\left(x_{i} \cup M^{\prime}\right) \cup R S\left(X_{i} \cup M\right) ; P_{7}=R S\left(x_{1}, x_{2} \ldots x_{m} \cup M^{\prime}\right) \cup R S\left(X_{1}, X_{2} \ldots X_{m} \cup\right.$ $M) \cup R S\left(Q_{m} \cup M\right)$

\section{Proof:}

Can be proved by direct verification.

\section{Proposition 3.4.12:}


The distance between the vertices of $P_{3}$ to the vertices of $P_{4}$ is given by $1 .\left(\left|P_{3}\right| .\left|P_{4}\right|\right)=$ 1. $\left[\left(2^{n-m}-1\right) \cdot\left(2^{m}-(m+2)\right)\right]$

Where $P_{3}=\left\{R S(Y) \mid Y \in M^{\prime}\right\} ; P_{4}=R S\left(x_{1}, x_{2} \ldots x_{r}\right)$

\section{Proof:}

Since the elements in $P_{3}$ contains maximum degree, which indicates that the distance from $P_{3}$ to $P_{4}, P_{5}, P_{6}$ and $P_{7}$ is 1 . Hence the distance from $P_{3}$ to $P_{4}$ is $1 .\left(\left|P_{3}\right| \cdot\left|P_{4}\right|\right)=1$. $\left[\left(2^{n-m}-\right.\right.$ 1). $\left.\left(2^{m}-(m+2)\right)\right]$

\section{Proposition 3.3.13:}

The distance between the vertices of $P_{3}$ to the vertices of $P_{5}$ is given by $1 .\left(\left|P_{3}\right| .\left|P_{5}\right|\right)=$ 1. $\left(2^{n-m}-1\right)$ where $P_{3}=\left\{R S(Y) \mid Y \in M^{\prime}\right\} ; P_{5}=R S\left(x_{1}, x_{2} \ldots x_{m}\right)$

\section{Proof:}

The proof is obvious from the Proposition 3.3.12

\section{Proposition 3.3.14:}

The distance between the vertices of $P_{3}$ to the vertices of $P_{6}$ is given by $1 .\left(\left|P_{3}\right| .\left|P_{6}\right|\right)=$ $\left[\left(2^{m}-(m+2)\left(2^{n+1-m}-1\right)\left(2^{n-m}-1\right)+3\left(2^{-(-n+m)}\right)\left(3^{m-1}+1-2^{m}\right)\right)\right]$ where

$$
P_{3}=\left\{R S(Y) \mid Y \in M^{\prime}\right\} ; P_{6}=R S\left(x_{1}, x_{2} \ldots x_{r} \cup M^{\prime}\right) \cup R S\left(X_{1}, X_{2} \ldots X_{r} \cup M\right) \cup R S\left(Q_{r} \cup M\right)
$$

\section{Proof:}

Can be proved by direct verification.

\section{Proposition 3.3.15:}

The distance between the vertices of $P_{3}$ to the vertices of $P_{7}$ is given by $1 .\left(\left|P_{3}\right| .\left|P_{7}\right|\right)=$ 1. $\left[\left(2^{n-m}-1\right) \cdot\left(2^{n-m}\left(2^{m}\right)-2\right)\right]$ where $P_{3}=\left\{R S(Y) \mid Y \in M^{\prime}\right\} ; P_{7}=R S\left(x_{1}, x_{2} \ldots x_{m} \cup M^{\prime}\right) \cup$ $R S\left(X_{1}, X_{2} \ldots X_{m} \cup M\right) \cup R S\left(Q_{m} \cup M\right)$

\section{Proof:}

Can be proved by direct verification.

\section{Proposition 3.3.16:}

The distance between the vertices of $P_{4}$ to the vertices of $P_{5}$ is given by $2 .\left(\left|P_{4}\right| .\left|P_{5}\right|\right)=$ 1. $\left[\left(2^{m}-m-2\right)\right]$ where $P_{4}=R S\left(x_{1}, x_{2} \ldots x_{r}\right)$ and $P_{5}=R S\left(x_{1}, x_{2} \ldots x_{m}\right)$

\section{Proof:}


None of the elements in $P_{4}$ is connected to $P_{5}$ with distance 1 because $1<r<m$.

Hence the distance from $P_{4}$ to $P_{5}$ is $2 .\left(\left|P_{4}\right| .\left|P_{5}\right|\right)=1 .\left[\left(2^{m}-m-2\right)\right]$.

\section{Proposition 3.3.17:}

The distance between the elements of $P_{4}$ to the vertices of $P_{6}$ is given by $\left|P_{4}\right|\left[1\right.$. $\left(\left|P_{6}\right|-\right.$ $(*+* *+* * *))+2 .(*+* *+* * *)]=2^{m}-(m+2)\left[1 .\left(2^{m}-(m+2)\left(2^{n+1-m+1}-1+\right.\right.\right.$ $\left.\left.3\left(2^{n-m}\right)\left(3^{m-3-2}-2^{m}+1\right)-(*+* *+* * *)\right)+2 .(*+* *+* * *)\right]$

where $P_{4}=R S\left(x_{1}, x_{2} \ldots x_{r}\right) \quad$ and $\quad P_{6}=R S\left(x_{1}, x_{2} \ldots x_{r} \cup M^{\prime}\right) \cup R S\left(X_{1}, X_{2} \ldots X_{r} \cup M\right) \cup$ $R S\left(Q_{r} \cup M\right)$

\section{Proof:}

Considering the partition $P_{4}$ is of the form $R S\left(x_{1}, x_{2} \ldots x_{r}\right)$ with $2^{m}-(m+2)$ elements, where $1<r<m$ and partition $P_{6}$ is an association of three set namely the first set is $R S\left(x_{1}, x_{2} \ldots x_{r} \cup M^{\prime}\right)$, the second set is $R S\left(X_{1}, X_{2} \ldots X_{r} \cup M\right)$ and the third set is $R S\left(Q_{r} \cup M\right)$.

For $r=2,3 \ldots(m-1)$ the total number of two element category in $P_{4}$ is $\frac{m(m-1)}{2}$, the total number of three element category in $P_{4}$ is $\frac{m(m-1)(m-2)}{2}-(1.2+2.3+\cdots+(m-2)(m-1))$ and so on beyond any doubt $(m-1)$ number of elements in 1 .

\section{Case1:}

Two element category in $P_{4}$ is connected to the first set of $P_{6}$ with distance 2 and is given by $\left[\frac{m(m-1)}{2}\right] \cdot\left[(m-2) C_{0}+(m-2) C_{1}+\cdots+(m-2) C_{m-3}\right]\left(2^{n-m}-1\right)$

Correspondingly the three element category in $P_{4}$ is connected to the first set of $P_{6}$ with distance 2 and is given by

$$
\left[\frac{m(m-1)(m-2)}{2}-1.2+2.3+\cdots(m-2)(m-1)\right] \cdot\left[(m-3) C_{0}+(m-3) C_{1}+\cdots+(m-\right.
$$

3) $\left.C_{m-4}\right]\left(2^{n-m}-1\right)$ and so on eventually $(m-1)$ element category in $P_{4}$ is connected to the first set of $P_{6}$ with distance 2 and is given by $\left[m(m(m-1)) \cdot\left(2^{n-m}-1\right)\right]$

Adding all we get

$$
\begin{aligned}
& \left\{\left[\frac{m(m-1)}{2}\right] \cdot\left[(m-2) C_{0}+(m-2) C_{1}+\cdots+(m-2) C_{m-3}\right]+\left[\frac{m(m-1)(m-2)}{2}-1 \cdot 2+2 \cdot 3+\right.\right. \\
& \cdots(m-2)(m-1)] \cdot\left[(m-3) C_{0}+(m-3) C_{1}+\cdots+(m-3) C_{m-4}\right]+\cdots+1 \cdot[m(m(m- \\
& \left.\left.1)) \cdot\left(2^{n-m}-1\right)\right]\right\} \cdots \cdots \cdots \cdots \cdots(*)
\end{aligned}
$$




\section{Case 2:}

Two element category in $P_{4}$ is connected to the first set of $P_{6}$ with distance 2 and is given by $\left[\frac{m(m-1)}{2}\right] \cdot\left[(m-2) C_{0}+(m-2) C_{1}+\cdots+(m-2) C_{m-3}\right]\left(2^{n-m}\right)$

Correspondingly the three element category in $P_{4}$ is connected to the first set of $P_{6}$ with distance 2 and is given by

$$
\left[\frac{m(m-1)(m-2)}{2}-1.2+2.3+\cdots(m-1)(m-2)\right] \cdot\left[(m-3) C_{0}+(m-3) C_{1}+\cdots+(m-\right.
$$

3) $\left.C_{m-4}\right]\left(2^{n-m}\right)$ and so on eventually $(m-1)$ element category in $P_{4}$ is connected to the first set of $P_{6}$ with distance 2 and is given by $\left[m(m(m-1)) \cdot\left(2^{n-m}\right)\right]$

Adding all we get

$\left\{\left[\frac{m(m-1)}{2}\right] \cdot\left[(m-2) C_{0}+(m-2) C_{1}+\cdots+(m-2) C_{m-3}\right]+\left[\frac{m(m-1)(m-2)}{2}-1.2+2.3+\right.\right.$ $\cdots(m-1)(m-2)] \cdot\left[(m-3) C_{0}+(m-3) C_{1}+\cdots+(m-3) C_{m-4}\right]+\cdots+[m(m(m-$ $\left.\left.1)) \cdot\left(2^{n-m}\right)\right]\right\} \ldots \ldots \ldots \ldots \ldots \ldots(* *)$

\section{Case 3:}

Two element category in $P_{4}$ is connected to the first set of $P_{6}$ with distance 2 and is given by $\left[\frac{m(m-1)}{2}\right]\left[\sum_{k=2}^{m-1} \sum_{i=1}^{k-1} k C_{i}\right]\left(2^{n-m}\right)$

Correspondingly the three element category in $P_{4}$ is connected to the first set of $P_{6}$ with distance 2 and is given by

$$
\left[\frac{m(m-1)(m-2)}{2}-1.2+2.3+\cdots(m-2)(m-1)\right] \cdot\left[\sum_{k=3}^{m-1} \sum_{i=1}^{k-1} k C_{i}\right]\left(2^{n-m}\right) \quad \text { and } \quad \text { so } \quad \text { on }
$$
eventually $(m-1)$ element category in $P_{4}$ is connected to the first set of $P_{6}$ with distance 2 and is given by $\left[m(m(m-1)) \cdot\left(2^{n-m}\right)\right]$

Adding all we get

$$
\begin{aligned}
& \left\{\left[\frac{m(m-1)}{2}\right]\left[\sum_{k=2}^{m-1} \sum_{i=1}^{k-1} k C_{i}\right]+\left[\frac{m(m-1)(m-2)}{2}-1.2+2.3+\cdots(m-2)(m-\right.\right. \\
& \left.1)] \cdot\left[\sum_{k=3}^{m-1} \sum_{i=1}^{k-1} k C_{i}\right]+\cdots+1\right\}\left(2^{n-m}\right) \ldots \ldots \ldots \ldots(* * *)
\end{aligned}
$$

Therefore the distance between the elements of $P_{4}$ to the vertices of $P_{6}$ is given by $\left|P_{4}\right|\left[1 .\left(\left|P_{6}\right|-(*+* *+* * *)\right)+2 .(*+* *+* * *)\right]$.

\section{Proposition 3.3.18:}


The distance between the vertices of $P_{4}$ to the vertices of $P_{7}$ is given by 2. $\left(\left|P_{4}\right| \cdot\left|P_{7}\right|\right)=$ 2. $\left[\left(2^{m}-(m+2)\right) \cdot\left(2^{n-m}\left(2^{m}\right)-2\right)\right]$ where $P_{4}=R S\left(x_{1}, x_{2} \ldots x_{r}\right)$

and $P_{7}=R S\left(x_{1}, x_{2} \ldots x_{m} \cup M^{\prime}\right) \cup R S\left(X_{1}, X_{2} \ldots X_{m} \cup M\right) \cup R S\left(Q_{m} \cup M\right)$

\section{Proof:}

None of the elements in $P_{4}$ is connected to $P_{7}$ with distance 1 .

Hence 2. $\left(\left|P_{4}\right| \cdot\left|P_{7}\right|\right)=2 \cdot\left[\left(2^{m}-(m+2)\right) \cdot\left(2^{n-m}\left(2^{m}\right)-2\right)\right]$.

\section{Proposition 3.3.19:}

The distance between the vertices of $P_{5}$ to the vertices of $P_{6}$ is given by $1 .\left(\left|P_{5}\right| \cdot\left|P_{6}\right|\right)=$ 1. $\left[\left(2^{m}-(m+2)\left(2^{n+1-m}-1\right)+3\left(2^{n-m}\right)\left(3^{m-5+4}-2^{m}+1\right)\right]\right.$ where $P_{5}=R S\left(x_{1}, x_{2} \ldots x_{m}\right)$ and $P_{7}=R S\left(x_{1}, x_{2} \ldots x_{r} \cup M^{\prime}\right) \cup R S\left(X_{1}, X_{2} \ldots X_{r} \cup M\right) \cup R S\left(Q_{r} \cup M\right)$

\section{Proof:}

In consequence $P_{5}$ has single element and it is connected to all the elements in $P_{6}$. Thus the distance from $P_{5}$ to $P_{6}$ is

1. $\left(\left|P_{5}\right| \cdot\left|P_{6}\right|\right)=1 \cdot\left[\left(2^{m}-(m+2)\left(2^{n+1-m}-1\right)+3\left(2^{n-m}\right)\left(3^{m-5+4}-2^{m}+1\right)\right]\right.$.

\section{Proposition 3.3.20:}

The distance between the vertices of $P_{5}$ to the vertices of $P_{7}$ is given by $2 .\left(\left|P_{5}\right| .\left|P_{6}\right|\right)=$ 1. $\left[2^{n-m}\left(2^{m}\right)-2\right]$ where $P_{5}=R S\left(x_{1}, x_{2} \ldots x_{m}\right)$

$$
\text { and } P_{7}=R S\left(x_{1}, x_{2} \ldots x_{m} \cup M^{\prime}\right) \cup R S\left(X_{1}, X_{2} \ldots X_{m} \cup M\right) \cup R S\left(Q_{m} \cup M\right)
$$

\section{Proof:}

Element in $P_{5}$ is connected to every elements in $P_{7}$ with distance 2. Hence 2. $\left(\left|P_{5}\right| \cdot\left|P_{7}\right|\right)=$ 2. $\left[2^{n-m}\left(2^{m}\right)-2\right]$.

\section{Proposition 3.3.21:}

The distance between the elements of $P_{6}$ to the elements of $P_{7}$ is given by $1 .\left(\left|P_{6}\right| .\left|P_{7}\right|\right)=$ 2. $\left[\left(2^{m}-(m+2)\left(2^{n-m+1}-1\right)+3\left(2^{n-m}\right)\left(3^{m-1}-2^{m}+1\right) \cdot\left(2^{n-m}\left(2^{m}\right)-2\right)\right]\right.$.

Where $P_{6}=R S\left(x_{1}, x_{2} \ldots x_{r} \cup M^{\prime}\right) \cup R S\left(X_{1}, X_{2} \ldots X_{r} \cup M\right) \cup R S\left(Q_{r} \cup M\right)$

$$
P_{7}=R S\left(x_{1}, x_{2} \ldots x_{m} \cup M^{\prime}\right) \cup R S\left(X_{1}, X_{2} \ldots X_{m} \cup M\right) \cup R S\left(Q_{m} \cup M\right)
$$

\section{Proof:}


All the elements in $P_{6}$ is connected with $P_{7}$ with distance 1. $\left(\left|P_{6}\right| \cdot\left|P_{7}\right|\right)=1 .\left[\left(2^{m}-(m+\right.\right.$ $\left.2)\left(2^{n-m+1}-1\right)+3\left(2^{n-m}\right)\left(3^{m-1}-2^{m}+1\right) \cdot\left(2^{n-m}\left(2^{m}\right)-2\right)\right]$

\section{Theorem 3.3.1:}

The wiener index $W\left(Z^{*}(J)\right)$ of Rough co-zero divisor graph $G\left(Z^{*}(J)\right)$, when $n \neq m$ is $(A)+$ $(B)+(C)$ where

$$
\begin{aligned}
& A=\left|P_{1}\right|\left\{1 .\left[\left|P_{2}\right|+\left|P_{3}\right|+\left|P_{4}\right|-\left(2^{n}-3\right)+(m-1) C_{r}\left(2^{-(-n+m)}-1\right)+\left(2^{n-m}\right)((m-\right.\right. \\
& \left.1) C_{r}+\sum_{r=2}^{m-1}\left((m-1) C_{1}+(m-1) C_{2}+\cdots+(m-1) C_{r-1}\right)\right]+2 \cdot\left[2^{m-1}-2^{n-m+2}+1+\right. \\
& \left|P_{5}\right|+\left|P_{6}\right|-(m-1) C_{r}\left(2^{-(-n+m)}-1\right)+\left(2^{n-m}\right)\left((m-1) C_{r}+\sum_{r=2}^{m-1}\left((m-1) C_{1}+(m-\right.\right. \\
& \left.\left.\left.\left.1) C_{2}+\cdots+(m-1) C_{r-1}\right)\right)\left(2^{-(-n+m}\right)+\left|P_{7}\right|\right]\right\}+\left|P_{2}\right|\left\{1 .\left[\left|P_{3}\right|+\left|P_{4}\right|+\left|P_{5}\right|+\left|P_{6}\right|+\left|P_{7}\right|\right]\right\}+ \\
& \left|P_{3}\right|\left\{1 .\left[\left|P_{4}\right|+\left|P_{5}\right|+\left|P_{6}\right|+\left|P_{7}\right|\right]\right\}+\left|P_{4}\right|\left\{1 .\left[\left(\left|P_{6}\right|-(*+* *+* * *)\right]+2 .\left[\left|P_{5}\right|+(*+* *+* *\right.\right.\right. \\
& \left.*)] .+\left|P_{7}\right|\right\}+\left|P_{5}\right|\left\{1 .\left|P_{6}\right|+2 .\left|P_{7}\right|\right\}+\left|P_{6}\right|\left\{1 .\left|P_{7}\right|\right\} \\
& B=\frac{1}{2}\left\{\left|P_{1}\right|\left(\left|P_{1}\right|-1\right)+\left|P_{2}\right|\left(\left|P_{2}\right|-1\right)+\left|P_{3}\right|\left(\left|P_{3}\right|-1\right)+\left|P_{5}\right|\left(\left|P_{5}\right|-1\right)+\left|P_{6}\right|\left(\left|P_{6}\right|-\right.\right. \\
& \left.1)+\left|P_{7}\right|\left(\left|P_{7}\right|-1\right)\right\} \\
& C=1 .\left[\frac{(m-1) m}{2}\right]+\left[\frac{m(m-1)(m-2)}{2}-1.2+2.3+\cdots+(m-1)(m-2)\right]+\cdots .+1+2 .\left\{\left(2^{m}-\right.\right. \\
& \left.(m+2))-\left[\frac{(m-1) m}{2}\right]+\left[\frac{(m-1)(m-2) m}{2}-1.2+2.3+\cdots+(m-1)(m-2)\right]+\cdots .+1\right\}
\end{aligned}
$$

\section{Proof:}

The wiener index of $G\left(Z^{*}(J)\right)$ is the sum of the distance from every vertex to every other vertex and hence from Proposition 3.3.1 to Proposition 3.3.21 we have

$$
\begin{aligned}
& \left|P_{1}\right|\left\{1 .\left[\left|P_{2}\right|+\left|P_{3}\right|+\left|P_{4}\right|-\left(2^{n}-3\right)+(m-1) C_{r}\left(2^{-(-n+m}-1\right)+(m-1) C_{r}+\right.\right. \\
& \left.\sum_{r=2}^{m-1}\left((m-1) C_{1}+(m-1) C_{2}+\cdots+(m-1) C_{r-1}\right)\left(2^{n-m}\right)\right]+2 .\left[2^{m-1}-2^{n-m+2}+1+\right. \\
& \left|P_{5}\right|+\left|P_{6}\right|-(m-1) C_{r}\left(2^{-(-n+m)}-1\right)+\left((m-1) C_{r}+\sum_{r=2}^{m-1}\left((m-1) C_{1}+(m-1) C_{2}+\right.\right. \\
& \left.\left.\left.\left.\cdots+(m-1) C_{r-1}\right)\right)\left(2^{n-m}\right)+\left|P_{7}\right|\right]\right\}+\left|P_{2}\right|\left\{1 .\left[\left|P_{3}\right|+\left|P_{4}\right|+\left|P_{5}\right|+\left|P_{6}\right|+\left|P_{7}\right|\right]\right\}+ \\
& \left|P_{3}\right|\left\{1 .\left[\left|P_{4}\right|+\left|P_{5}\right|+\left|P_{6}\right|+\left|P_{7}\right|\right]\right\}+\left|P_{4}\right|\left\{1 .\left[\left(\left|P_{6}\right|-(*+* *+* * *)\right)\right]+2 .\left[\left|P_{5}\right|+\right.\right. \\
& \left.(*+* *+* * *)] .+\left|P_{7}\right|\right\}+\left|P_{5}\right|\left\{1 .\left|P_{6}\right|+2 .\left|P_{7}\right|\right\}+\left|P_{6}\right|\left\{1 .\left|P_{7}\right|\right\} \ldots \ldots \ldots \ldots(A)
\end{aligned}
$$

Proposition 3.3.1 to 3.3.21, gives the distance from one partition to every other partition. Hence equation $(A)$ gives the distance from the vertices of one partition to vertices of every other partition. Also note that the vertices of $P_{1}, P_{2}, P_{3}, P_{5}, P_{6}$ and $P_{7}$ form a complete subgraph of $G\left(Z^{*}(J)\right)$. Therefore the distances between the vertices in each of these partition in each of these partition are one. Hence the sum of such distance is given by $\frac{n(n-1)}{2}$ where $n=\left|P_{i}\right|$ for $i=$ $1,2,3,5,6,7$ which is calculated by $\frac{\left|P_{i}\right|\left(\left|P_{i}\right|-1\right)}{2}$ 
(i.e) $\frac{\left|P_{1}\right|\left(\left|P_{1}\right|-1\right)}{2}+\frac{\left|P_{2}\right|\left(\left|P_{2}\right|-1\right)}{2}+\frac{\left|P_{3}\right|\left(\left|P_{3}\right|-1\right)}{2}+\frac{\left|P_{5}\right|\left(\left|P_{5}\right|-1\right)}{2}+\frac{\left|P_{6}\right|\left(\left|P_{6}\right|-1\right)}{2}+\frac{\left|P_{7}\right|\left(\left|P_{7}\right|-1\right)}{2}$

$\frac{1}{2}\left\{\left|P_{1}\right|\left(\left|P_{1}\right|-1\right)+\left|P_{2}\right|\left(\left|P_{2}\right|-1\right)+\left|P_{3}\right|\left(\left|P_{3}\right|-1\right)+\left|P_{5}\right|\left(\left|P_{5}\right|-1\right)+\left|P_{6}\right|\left(\left|P_{6}\right|-1\right)+\right.$ $\left.\left|P_{7}\right|\left(\left|P_{7}\right|-1\right)\right\}$

Now when $\mathrm{i}=4$, we need to find the distance between the vertices in $\left|\mathrm{P}_{4}\right|$. Note that $\mathrm{P}_{4}=$ $\mathrm{RS}\left(\mathrm{x}_{1}, \mathrm{x}_{2} \ldots \mathrm{x}_{\mathrm{r}}\right)$. Hence we calculate the distance within the vertices of $\mathrm{P}_{4}$ is

1. $\left[\frac{(m-1) m}{2}\right]+\left[\frac{(m-1)(m-2) m}{2}-1.2+2.3+\cdots+(m-1)(m-2)\right]+\cdots \cdot+1+2 \cdot\left\{\left(2^{m}-\right.\right.$

$\left.(m+2))-\left[\frac{(m-1) m}{2}\right]+\left[\frac{m(m-1)(m-2)}{2}-1.2+2.3+\cdots+(m-1)(m-2)\right]+\cdots .+1\right\}$

The wiener index of $G\left(Z^{*}(J)\right)$ is obtained as by using $(A)+(B)+(C)$ we get

$W\left(Z^{*}(J)\right)=\left|P_{1}\right|\left\{1 .\left[\left|P_{2}\right|+\left|P_{3}\right|+\left|P_{4}\right|-\left(2^{n}-3\right)+(m-1) C_{r}\left(2^{n-m}-1\right)+(m-\right.\right.$ 1) $\left.C_{r}\left(2^{n-m}\right)+\left(2^{n-m}\right) \sum_{r=2}^{m-1}\left((m-1) C_{1}+(m-1) C_{2}+\cdots+(m-1) C_{r-1}\right)\right]+2 \cdot\left[2^{m-1}-\right.$ $2^{n-m+2}+1+\left|P_{5}\right|+\left|P_{6}\right|-(m-1) C_{r}\left(2^{n-m}-1\right)+(m-1) C_{r}\left(2^{n-m}\right)+$ $\left.\left.\left(2^{n-m}\right) \sum_{r=2}^{m-1}\left((m-1) C_{1}+(m-1) C_{2}+\cdots+(m-1) C_{r-1}\right)+\left|P_{7}\right|\right]\right\}+\left|P_{2}\right|\left\{1 .\left[\left|P_{3}\right|+\left|P_{4}\right|+\right.\right.$ $\left.\left.\left|P_{5}\right|+\left|P_{6}\right|+\left|P_{7}\right|\right]\right\}+\left|P_{3}\right|\left\{1 .\left[\left|P_{4}\right|+\left|P_{5}\right|+\left|P_{6}\right|+\left|P_{7}\right|\right]\right\}+\left|P_{4}\right|\left\{1 .\left[\left(\left|P_{6}\right|-(*+* *+* * *)\right)\right]+\right.$ 2. $\left.\left[\left|P_{5}\right|+(*+* *+* * *)\right] .+\left|P_{7}\right|\right\}+\left|P_{5}\right|\left\{1 .\left|P_{6}\right|+2 .\left|P_{7}\right|\right\}+\left|P_{6}\right|\left\{1 .\left|P_{7}\right|\right\}+\frac{1}{2}\left\{\left|P_{1}\right|\left(\left|P_{1}\right|-1\right)+\right.$ $\left.\left|P_{2}\right|\left(\left|P_{2}\right|-1\right)+\left|P_{3}\right|\left(\left|P_{3}\right|-1\right)+\left|P_{5}\right|\left(\left|P_{5}\right|-1\right)+\left|P_{6}\right|\left(\left|P_{6}\right|-1\right)+\left|P_{7}\right|\left(\left|P_{7}\right|-1\right)\right\}+$ 1. $\left[\frac{m(m-1)}{2}\right]+\left[\frac{m(m-1)(m-2)}{2}-1.2+2.3+\cdots(m-2)(m-1)\right]+\cdots \cdot+1+2 \cdot\left\{\left(2^{m}-(m+\right.\right.$ 2)) $\left.-\left[\frac{m(m-1)}{2}\right]+\left[\frac{m(m-1)(m-2)}{2}-1.2+2.3+\cdots(m-2)(m-1)\right]+\cdots .+1\right\} \cdots(I)$

\section{Theorem 3.3.2:}

The wiener index $W\left(Z^{*}(J)\right)$ of Rough co-zero divisor graph $G\left(Z^{*}(J)\right)$, when $n=m$ is

$\left|P_{1}\right|\left\{1 .\left[\left|P_{2}\right|+\left|P_{4}\right|-\left(2^{n}-3\right)+(m-1) C_{r}\left(2^{n-m}-1\right)+(m-1) C_{r}\left(2^{n-m}\right)+\right.\right.$ $\left.\left(2^{n-m}\right) \sum_{r=2}^{m-1}\left((m-1) C_{1}+(m-1) C_{2}+\cdots+(m-1) C_{r-1}\right)\right]+2 \cdot\left[2^{m-1}-2^{n-m+2}+1+\right.$ $\left|P_{5}\right|+\left|P_{6}\right|-(m-1) C_{r}\left(2^{n-m}-1\right)+(m-1) C_{r}\left(2^{n-m}\right)+\left(2^{n-m}\right) \sum_{r=2}^{m-1}\left((m-1) C_{1}+(m-\right.$ 1) $\left.\left.\left.C_{2}+\cdots+(m-1) C_{r-1}\right)+\left|P_{7}\right|\right]\right\}+\left|P_{2}\right|\left\{1 .\left[+\left|P_{4}\right|+\left|P_{5}\right|+\left|P_{6}\right|+\left|P_{7}\right|\right]\right\}+\left|P_{4}\right|\left\{1 .\left[\left(\left|P_{6}\right|-(*\right.\right.\right.$ $\left.+* *+* * *))]+2 .\left[\left|P_{5}\right|+(*+* *+* * *)\right] .+\left|P_{7}\right|\right\}+\left|P_{5}\right|\left\{1 .\left|P_{6}\right|+2 .\left|P_{7}\right|\right\}+\left|P_{6}\right|\left\{1 .\left|P_{7}\right|\right\}+$ $\frac{1}{2}\left\{\left|P_{1}\right|\left(\left|P_{1}\right|-1\right)+\left|P_{2}\right|\left(\left|P_{2}\right|-1\right)++\left|P_{5}\right|\left(\left|P_{5}\right|-1\right)+\left|P_{6}\right|\left(\left|P_{6}\right|-1\right)+\left|P_{7}\right|\left(\left|P_{7}\right|-1\right)\right\}+$ 1. $\left[\frac{m(m-1)}{2}\right]+\left[\frac{m(m-1)(m-2)}{2}-1.2+2.3+\cdots(m-2)(m-1)\right]+\cdots \cdot+1+2 .\left\{\left(2^{m}-(m+\right.\right.$ 2)) $\left.-\left[\frac{m(m-1)}{2}\right]+\left[\frac{m(m-1)(m-2)}{2}-1.2+2.3+\cdots(m-2)(m-1)\right]+\cdots .+1\right\}$.

\section{Proof:}


Now we calculate the wiener index of Rough co-zero divisor graph $G\left(Z^{*}(J)\right)$ when $n=m$. Since $P_{3}=\emptyset$. Therefore by a similar calculation on leaving $P_{3}$ the wiener index of $G\left(Z^{*}(J)\right)$ is $W\left(Z^{*}(J)\right)=\left|P_{1}\right|\left\{1 \cdot\left[\left|P_{2}\right|+\left|P_{4}\right|-\left(2^{n}-3\right)+(m-1) C_{r}\left(2^{n-m}-1\right)+(m-1) C_{r}\left(2^{n-m}\right)+\right.\right.$ $\left.\left(2^{n-m}\right) \sum_{r=2}^{m-1}\left((m-1) C_{1}+(m-1) C_{2}+\cdots+(m-1) C_{r-1}\right)\right]+2 \cdot\left[2^{m-1}-2^{n-m+2}+1+\right.$ $\left|P_{5}\right|+\left|P_{6}\right|-(m-1) C_{r}\left(2^{n-m}-1\right)+(m-1) C_{r}\left(2^{n-m}\right)+\left(2^{n-m}\right) \sum_{r=2}^{m-1}\left((m-1) C_{1}+(m-\right.$ 1) $\left.\left.\left.C_{2}+\cdots+(m-1) C_{r-1}\right)+\left|P_{7}\right|\right]\right\}+\left|P_{2}\right|\left\{1 .\left[+\left|P_{4}\right|+\left|P_{5}\right|+\left|P_{6}\right|+\left|P_{7}\right|\right]\right\}+\left|P_{4}\right|\left\{1 .\left[\left(\left|P_{6}\right|-(*\right.\right.\right.$ $\left.+* *+* * *))]+2 .\left[\left|P_{5}\right|+(*+* *+* * *)\right] .+\left|P_{7}\right|\right\}+\left|P_{5}\right|\left\{1 .\left|P_{6}\right|+2 .\left|P_{7}\right|\right\}+\left|P_{6}\right|\left\{1 .\left|P_{7}\right|\right\}+$ $\frac{1}{2}\left\{\left|P_{1}\right|\left(\left|P_{1}\right|-1\right)+\left|P_{2}\right|\left(\left|P_{2}\right|-1\right)++\left|P_{5}\right|\left(\left|P_{5}\right|-1\right)+\left|P_{6}\right|\left(\left|P_{6}\right|-1\right)+\left|P_{7}\right|\left(\left|P_{7}\right|-1\right)\right\}+$ 1. $\left[\frac{m(m-1)}{2}\right]+\left[\frac{m(m-1)(m-2)}{2}-1.2+2.3+\cdots(m-2)(m-1)\right]+\cdots \cdot+1+2 \cdot\left\{\left(2^{m}-(m+\right.\right.$ $\left.2))-\left[\frac{m(m-1)}{2}\right]+\left[\frac{m(m-1)(m-2)}{2}-1.2+2.3+\cdots(m-2)(m-1)\right]+\cdots .+1\right\} \cdots \cdots \cdots .(I I)$

\section{Example 3.3.1}

From Example 3.2.1 we have $n=m=3$ by substituting all the values in equation (II) we get

$$
\begin{aligned}
W\left(Z^{*}(J)\right)=2 & \{1 .(3)+2 .(3)\}+1 .(1.2)+2(2.1)+2 .(2.6)+1 .(6.1)+1 .(6.1)+1 .(1.1) \\
& +1 .(1.6)+2 .(1.6)+(1+15+15) \\
=18+2+4+ & 24+6+6+36+1+6+12+31=146
\end{aligned}
$$

when $n=m=3$, the wiener index $W\left(Z^{*}(J)\right)$ of $G\left(Z^{*}(J)\right)$ is obtained by 146

\section{Example 3.3.2}

From Example 3.2.2 we have $n=m=3$ by substituting all the values in equation (II) we get

$$
\begin{aligned}
& W\left(Z^{*}(J)\right)=3\{1 .(3-2+1)+2 .(-2+1)\}+3\{1 .(3-2)+2 .(2)\}+2(3.1) \\
& +3\{1 .(3)+2 .(9-(3))\}+2 .\{(3.6)+1 .\{(3.3)+1 .\{(3.1)+1 .\{(3.9) \\
& +1 .\{(3.6)+2 .\{(3.1)+\{1.18+2.9+2 .\{(3.6)+2 .\{(1.6)+1 .\{(9.6)\} \\
& +\{1.3+1.3+1.3+1.0+1.36+1.15\} \\
& =12+15+6+45+36+9+3+27+18+6+36+36+9+12+54+60=384
\end{aligned}
$$

when $n=m=3$, the wiener index $W\left(Z^{*}(J)\right)$ of $G\left(Z^{*}(J)\right)$ is obtained by 384 .

\section{APPLICATION}

Let $U$ be the set of symptoms namely Dry cough $\left(u_{1}\right)$, fever $\left(u_{2}\right)$, shortness of breath $\left(u_{3}\right)$, fatigue $\left(u_{4}\right)$, runny nose $\left(u_{5}\right)$, nasal congestion $\left(u_{6}\right)$, diarrhea $\left(u_{7}\right)$, body aches $\left(u_{8}\right)$, sore throat $\left(u_{9}\right)$, head ache $\left(u_{10}\right)$, loss of appetite $\left(u_{11}\right)$, new loss of taste or smell $\left(u_{12}\right)$, respiratory issues $\left(u_{13}\right)$, nausea $\left(u_{14}\right)$, vomiting $\left(u_{15}\right)$, high temperature $\left(u_{16}\right)$, sleeping disorders $\left(u_{17}\right)$, difficulty of breathing $\left(u_{18}\right)$ and sudden weight loss $\left(u_{19}\right)$. 


$$
\begin{gathered}
X_{1}=\left\{u_{1}, u_{2}\right\} ; X_{2}=\left\{u_{3}, u_{11}, u_{18}\right\} ; X_{3}=\left\{u_{7}, u_{14}, u_{15}\right\} ; X_{4}=\left\{u_{5}, u_{12}, u_{16}, u_{17}\right\} ; \\
X_{5}=\left\{u_{6}, u_{8}, u_{9}, u_{13}\right\} ; X_{6}=\left\{u_{4}, u_{10}\right\} ; X_{7}=\left\{u_{19}\right\}
\end{gathered}
$$

Let $\mathrm{D}$ be the set of diseases Influenza $d_{1}$, Common cold $d_{2}$, COVID-19 $d_{3}$, Pneumonia $d_{4}$, Asthma $d_{5}$, Acute bronchitis $d_{6}$, and Malaria $d_{7}$.

If $X=\{$ Cough, sleeping disorders $\}$ then $R S(X)=\left(\varnothing, X_{1} \cup X_{1}\right)$ means two symptoms together cannot confirm $d_{1}$ and $d_{3}$ but these two are the symptoms possibility of either $d_{1}$ or $d_{3}$. $X=\{$ Cough, cold, sore throat $\}$ then $R S(X)=\left(X_{1}, X_{1}\right)$ means confirms $d_{3}$. A similar interpretation can be given for all the Rough sets in $T^{*}$. If $R S(X)$ is any vertex in $G\left(Z^{*}(J)\right)$ then among the symptoms in $U$ we are able to identify a subset $Y$ that does not have any common symptoms with $X$ along with $J$ such elements are connected in $G\left(Z^{*}(J)\right)$. Also people who have a symptom associated with other symptom of disease is distance 2 and people who have a symptom not associated with other symptom of disease is distance 1 .

\section{CONCLUSION}

The focus of this study was to develop an innovative methodology for finding Degree, Distance and Wiener index of a Rough Co-zero divisor graph using partition graph. All aforesaid concepts are illustrated through examples. Our forthcoming work is to explore this partition graph to Rough Co-zero divisor graph.

\section{ACKNOWLEDGMENT}

The authors are deeply thankful to the Management, SSN Institution for the support towards the victorious achievement.

\section{REFERENCES}

[1]. Ansari-Toroghy, H., Farshadifar, F., \& Mahboobi-Abkenar, F. (2016). An ideal-based cozero-divisor graph of a commutative ring, pp. 45-54

[2]. Donno, A. (2017). Spectrum, distance spectrum, and Wiener index of wreath products of complete graphs. Ars Mathematica Contemporanea, 13(1), 207-225.

[3]. Dankelmann, P., Gutman, I., Mukwembi, S., \& Swart, H. C. (2009). The edge-Wiener index of a graph. Discrete Mathematics, 309(10), 3452-3457.

[4]. Dankelmann, P., Morgan, M. J., Mukwembi, S., \& Swart, H. C. (2014). On the eccentric connectivity index and Wiener index of a graph. Quaestiones Mathematicae, 37(1), 39-47. 
[5]. Eliasi, M., Raeisi, G., \& Taeri, B. (2012). Wiener index of some graph operations. Discrete Applied Mathematics, 160(9), 1333-1344.

[6]. Hua, H. (2020). Comparing multiplicative Wiener index with other graph invariants. MATCH Commun. Math. Comput. Chem, 83, 95-107.

[7]. Praba, B. (2021). Clique number and Girth of the Rough Co-zero Divisor Graph. Turkish Journal of Computer and Mathematics Education (TURCOMAT), 12(11), 5459-5466.

[8]. Afkhami, M., \& Khashyarmanesh, K. (2011). The Cozero-divisor Graph of a Commutative Ring. Southeast Asian Bulletin of Mathematics, 35(5), 935-944.

[9]. Praba, B., Manimaran, A., \& Chandrasekaran, V. M. (2015). The zero divisor graph of a rough semiring. International Journal of Pure and Applied Mathematics, 98(5), 33-37.

[10]. Praba, B. (2021). Clique number and Girth of the Rough Co-zero Divisor Graph. Turkish Journal of Computer and Mathematics Education (TURCOMAT), 12(11), 5459-5466.

[11]. Praba, B., \& Obilia, X. A. B. (2019). An application of category graph in finding the Wiener index of rough ideal based rough edge Cayley graph. Applied Mathematics and Information Sciences, 313-323.

[12]. Pawlak, Z. (1982). Rough sets. International journal of computer \& information sciences, 11(5), 341-356.

[13]. Xu, K., Liu, M., Das, K. C., Gutman, I., \& Furtula, B. (2014). A survey on graphs extremal with respect to distance-based topological indices. MATCH Commun. Math. Comput. Chem, 71(3), 461-508. 